\title{
Cementos que contienen 20 y 30 por ciento de cenizas volantes de Puentes de García Rodríguez y de Ponferrada
}

MARIA JESUS SANTOS CASTRO

\section{NOTA PREVIA}

La Dirección Técnica de "CEMENTOS NOROESTE, S. A." que se ocupa del estudio de los materiales y de los procesos desea agradecer públicamente al Prof. Dr. José CALLEJA, del IETCC, la valiosa colaboración y ayuda que a lo largo de bastantes años, desde 1973, viene prestando asíduamente en los trabajos de investigación sobre cementos con cenizas volantes, los cuales se llevan a cabo a partir de dicha fecha en la fábrica de OURAL (Lugo), así como en las publicaciones a las que estos trabajos van dando lugar. En particular, la autora de la presente comunicación hace constar su reconocimiento al Prof. CALLEJA por sus consejos y orientaciones para la misma

\section{N T R O D U C C I O N}

En las proximidades de nuestra factoría de Oural, dos centrales térmicas producen importantes cantidades de cenizas volantes.

En Puentes de García Rodríguez aproximadamente 3 millones de t/año y en Ponferrada aproximadamente 0,7 millones de t/año.

Las primeras proceden de la combustión de lignitos y las segundas de la combustión de antracitas y semihullas. Ambas son homogéneas en su comportamiento, pero poseen propiedades muy distintas que las diferencian perfectamente unas de otras.

En el presente trabajo intentamos estudiarlas a fin de conocer su posible aplicación en la fabricación de cementos, adicionándolas en el molino de clínker.

\section{MATERIALES DE PARTIDA}

\subsection{Cenizas volantes}




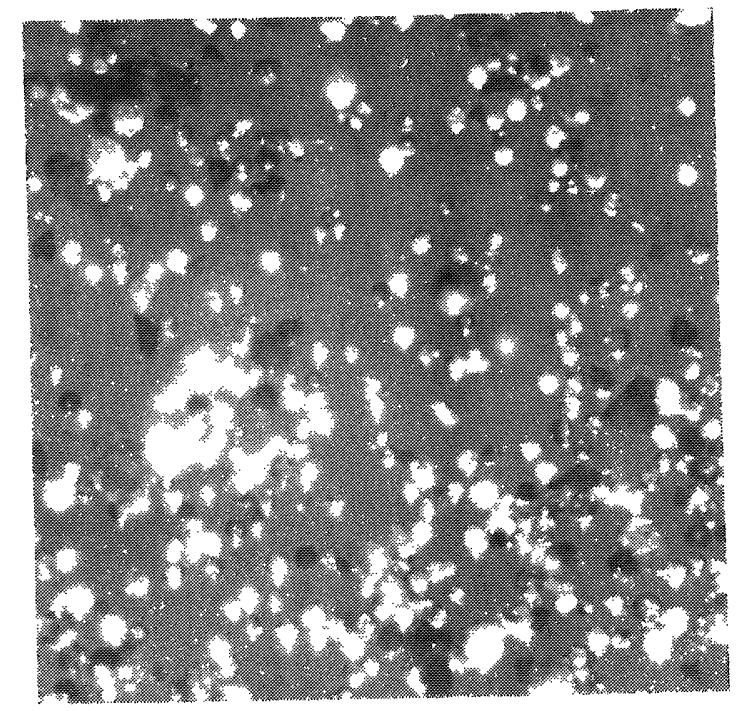

Fotografia 1- Tentzas de Ponferrada.

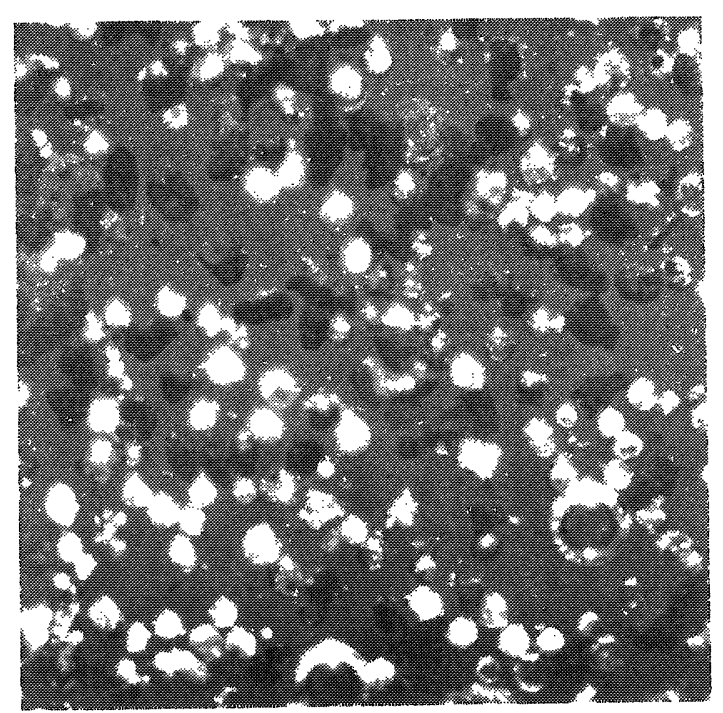

wotograíia 2.- Tentzas de Ponferrada.

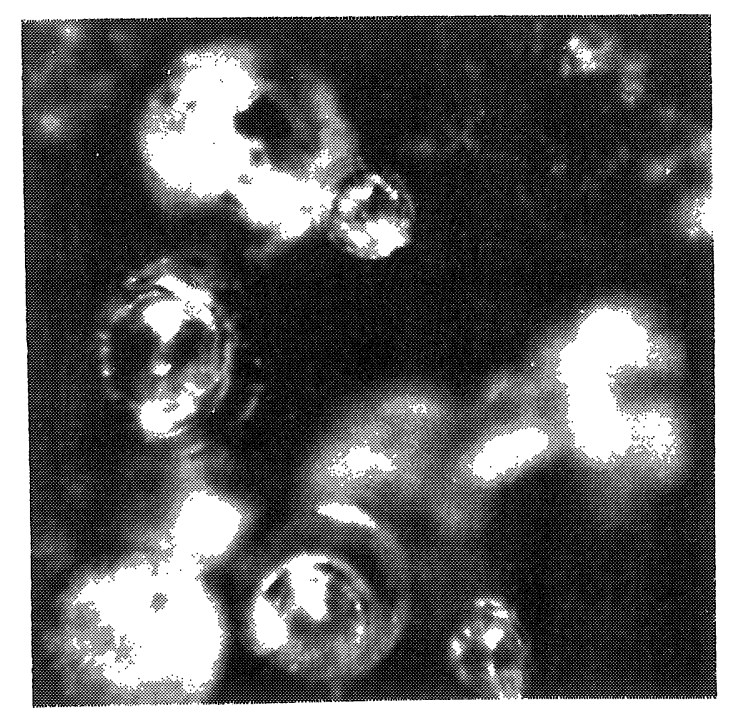

Fotografia 3.-cenizas de ponferrada.

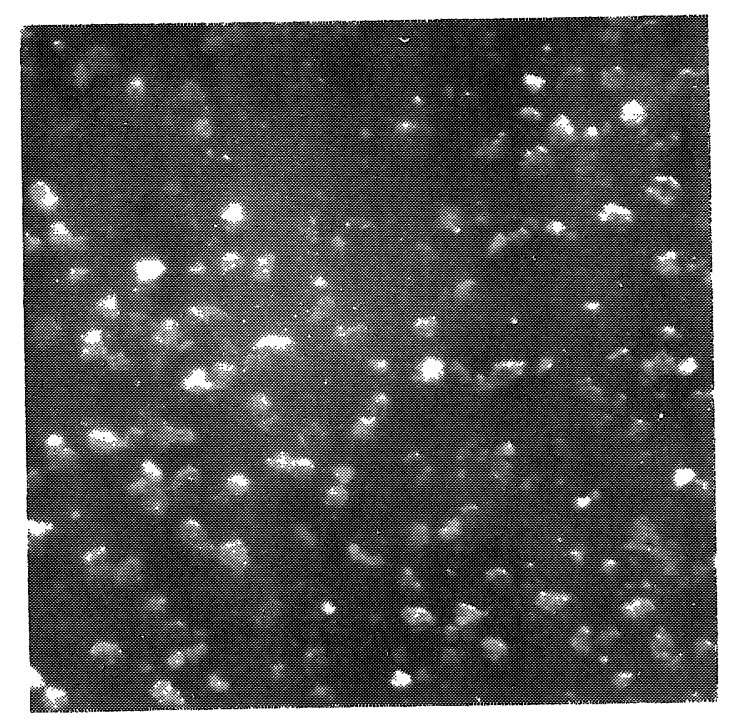

fotograpia 4.-Cenizas de ${ }^{2}$ uentes de Garcia Rodriguez.

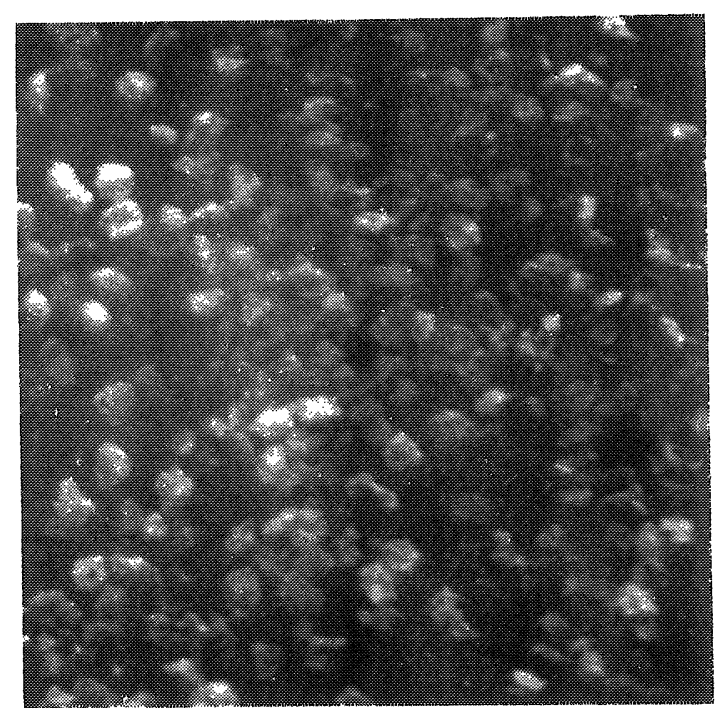

Fotograria 5.-Cenizas de Puentes de Garcia Rodriguez.

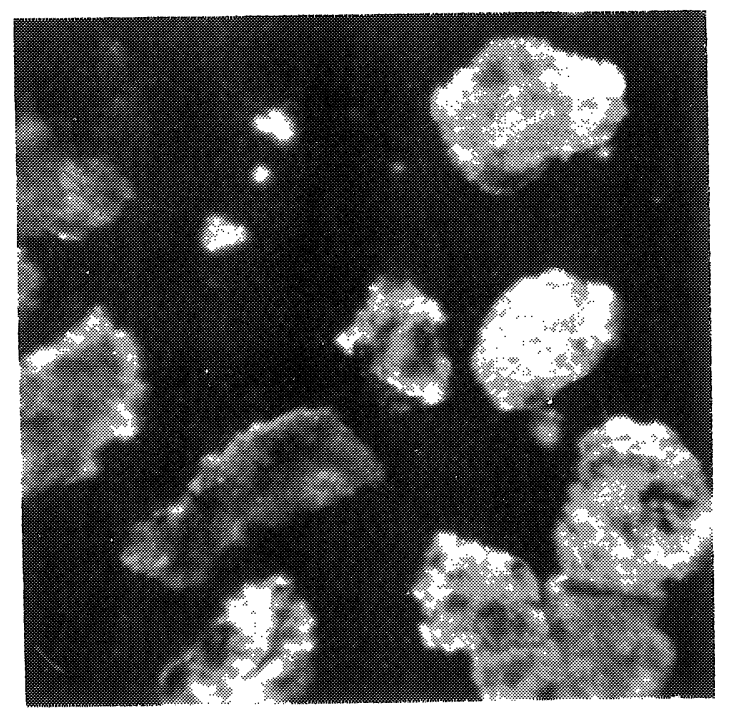

Eotograpia 6.-Cenizas de Puentes de Garcia Rodriguex: 
1.1.1. Cenizas de Puentes de García Rodriguez y de Ponferrada. Observaciones con microscopio

Las fotografías 1,2 y 3 corresponden a cenizas de Ponferrada. Se observan abundantes partículas en forma de esferas y con superficies muy pulidas (bolas vítreas o cenosferas).

Las fotografías 4, 5 y 6 corresponden a cenizas de Puentes. Los gránulos presentan superficies rugosas.

1.1.2. Análisis químico (según PCCH-64, apartado 2.7.)

Cenizas de Puentes Cenizas de Ponferrada

\begin{tabular}{|c|c|c|}
\hline $\begin{array}{llllllll}\text { Pérdida al fuego } & \ldots & \ldots & \ldots & \ldots & \ldots & \ldots & \ldots\end{array}$ & 3,2 & 6,3 \\
\hline $\begin{array}{lllllllll}\text { Residuo insoluble } & . . & \ldots & \ldots & \ldots & \ldots & \ldots & \ldots\end{array}$ & 41,8 & 59,0 \\
\hline $\begin{array}{llllllllllll}\mathrm{SO}_{3} & \ldots & \ldots & \ldots & \ldots & \ldots & \ldots & \ldots & \ldots & \ldots & \ldots & \ldots\end{array}$ & 0,9 & 0,5 \\
\hline $\begin{array}{llllllllllll}\mathrm{SiO}_{2} & \ldots & \ldots & \ldots & \ldots & \ldots & \ldots & \ldots & \ldots & \ldots & \ldots & \ldots\end{array}$ & 20,8 & 13,2 \\
\hline $\begin{array}{lllllllllllll}\mathrm{Al}_{2} \mathrm{O}_{3} & \ldots & \ldots & \ldots & \ldots & \ldots & \ldots & \ldots & \ldots & \ldots & \ldots & \ldots\end{array}$ & 17,2 & 9,0 \\
\hline $\begin{array}{llllllllllll}\mathrm{Fe}_{2} \mathrm{O}_{3} & \ldots & \ldots & \ldots & \ldots & \ldots & \ldots & \ldots & \ldots & \ldots & \ldots & \ldots\end{array}$ & 8,6 & 3,5 \\
\hline $\begin{array}{cccccccccccc}\mathrm{CaO} & \ldots & \ldots & \ldots & \ldots & \ldots & \ldots & \ldots & \ldots & \ldots & \ldots & \ldots\end{array}$ & 2,7 & 1,4 \\
\hline 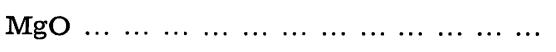 & 3,2 & 3,5 \\
\hline $\begin{array}{cccccccccccc}\mathrm{K}_{2} \mathrm{O} & \ldots & \ldots & \ldots & \ldots & \ldots & \ldots & \ldots & \ldots & \ldots & \ldots & \ldots\end{array}$ & 1,1 & 2,5 \\
\hline $\begin{array}{lllllllllllll}\mathrm{Na}_{2} \mathrm{O} & \ldots & \ldots & \ldots & \ldots & \ldots & \ldots & \ldots & \ldots & \ldots & \ldots & \ldots\end{array}$ & 0,2 & 0,6 \\
\hline
\end{tabular}

En Francia existen cenizas volantes procedentes de la combustión de lignitos que contienen cantidades importantes de $\mathrm{CaO}$. En nuestro caso, ambas cenizas contienen muy poco $\mathrm{CaO}$

\subsubsection{Granulometría original}

Determinada mediante la tamizadora Alpine, por barrido de aire.

\begin{tabular}{ccc}
$\begin{array}{c}\% \text { retenido en el tamiz } \\
\text { luz de malla (en } \mu \text { ) }\end{array}$ & $\begin{array}{c}\text { Cenizas de Puentes } \\
\%\end{array}$ & $\begin{array}{c}\text { Cenizas de Ponferrada } \\
\%\end{array}$ \\
\hline 200 & 4,0 & 0,2 \\
120 & 14,5 & 1,4 \\
90 & 24,0 & 3,6 \\
60 & 42,2 & 9,9 \\
45 & 60,5 & 18,7 \\
35 & 71,7 & 33,3
\end{tabular}

1.1.4. Densidad real original (según PCCH-64, apartado 2.3.)

$$
2,30 \mathrm{gr} / \mathrm{cm}^{3} \quad 2,28 \mathrm{gr} / \mathrm{cm}^{3}
$$

1.1.5. Las propiedades de las cenizas están muy relacionadas con su superficie específica 
Nosotros, en un molino de bolas de laboratorio, hemos molido ambas cenizas durante el mismo tiempo (dos horas). La f:nura y densidad real alcanzaron los valores que a continuación exponemos.

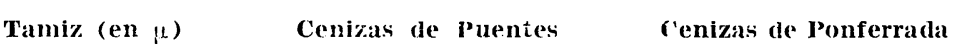

Granulometría medida mediante tamizadora Alpine

$\begin{array}{rrr}2 C 0 & 0,2 & 0,0 \\ 120 & 0,8 & 0,0 \\ 90 & 2,0 & 0,1 \\ 60 & 7,1 & 0,7 \\ 40 & 15,3 & 3,4 \\ 33 & 27,5 & 10,8\end{array}$

Determinada mediante la pipeta de Andreasen

$\begin{array}{lrr}40 & 21,0 & 11,8 \\ 50 & 23,5 & 27,5 \\ 20 & -57,1 & 57,9 \\ 15 & 70,3 & 69,4 \\ 8 & 82,6 & 88,7 \\ & & \\ \text { Densidad real } & 2,50 \mathrm{~g} / \mathrm{cm}^{3} & 2,46 \mathrm{~g} / \mathrm{cm}^{3}\end{array}$

En el gráfico de la figura 1 representamos las curvas granulométricas de ambas cenizas moli.das.

Hemos intentado moler las cenizas volantes hasta alcanzar un grado de finura semejante al que se obtiene en nuestros molinos a escala industrial cuando se desea fabricar cementos de categoría 350 , moliendo conjuntamente clínker, yeso y ceniza en proporción aproximada de 75,5 y $20 \%$ respectivamente.

\subsection{Cemento}

El cemento de partida es una muestra representativa del cemento que en el período de dos años se fabricó en las instalaciones de Oural con la designación P-350 y que en este trabajo llamaremos cemento T. Se obtuvo por molturación conjunta de clínker, piedra de yeso crudo y las cenizas volantes anteriormente descritas, en proporciones de mezcla aproximada de 85,5 y $10 \%$ respectivamente.

Cumple la norma PCCH-64 en todas sus prescripciones, a excepción del residuo insoluble. como: consecuencia de la presencia de cenizas (ver análisis químico del punto 1.1.2.).

1.2.1. Análisis químico (según PCCH-64. apartado 2.7.).

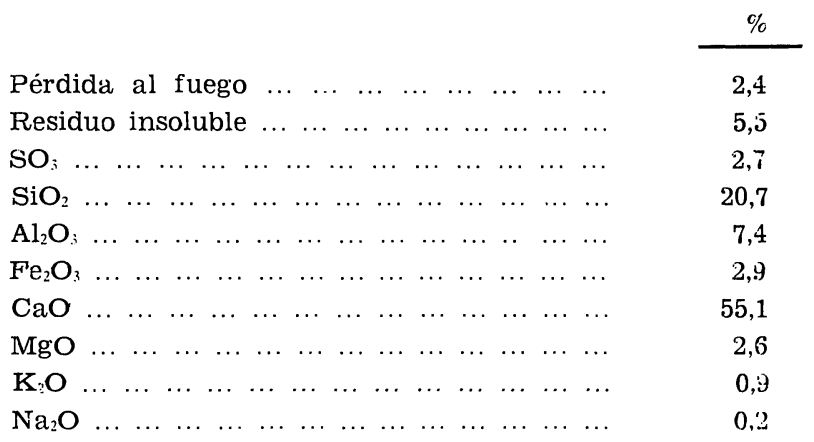

12 
GRANULOMETRIA

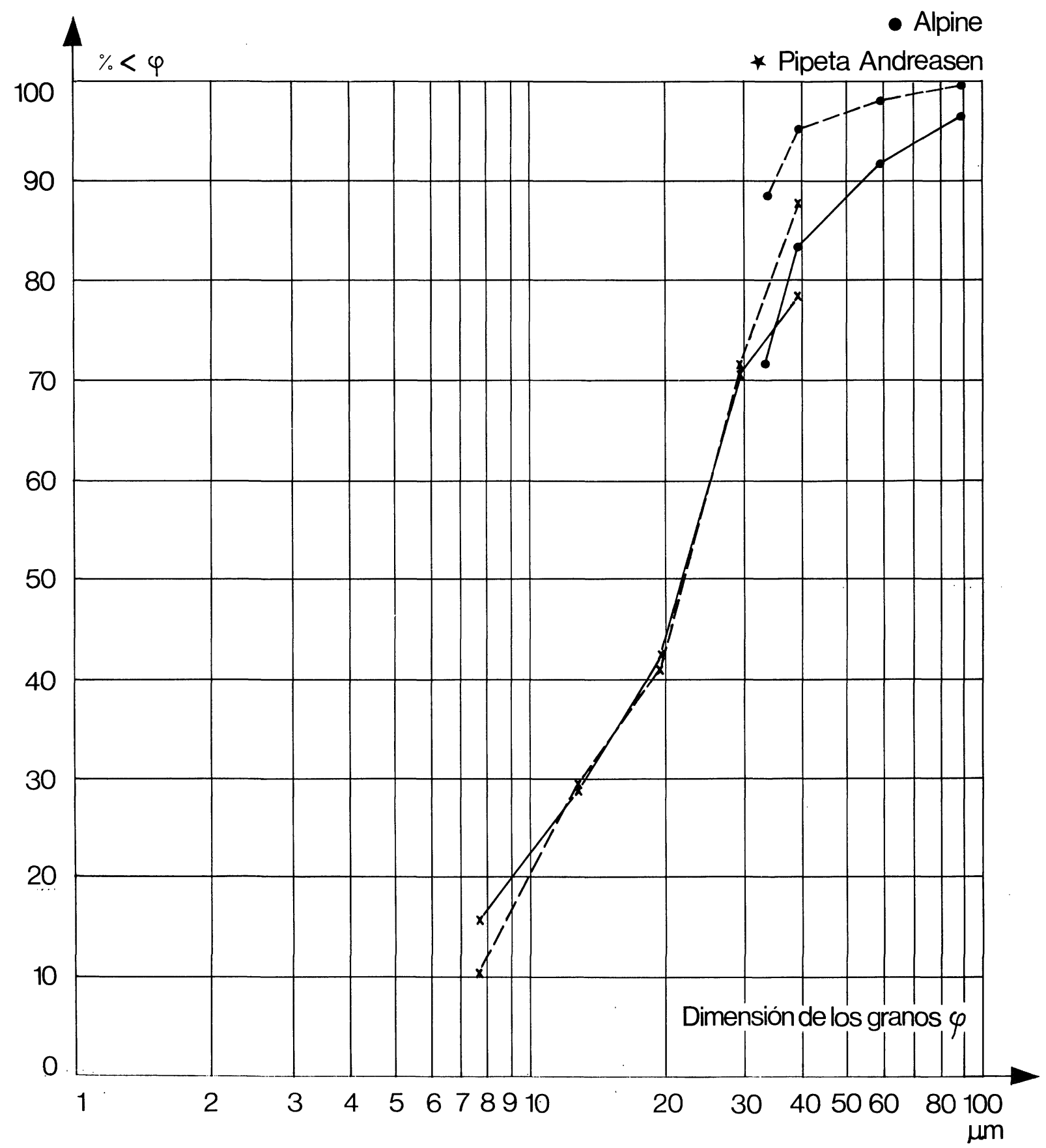

CENIZA de PUENTES (molida)

Flg. 1 
1.2.2. Indice puzolánico (según PCCH-64, apartado 2.733)

i días

67,8

7,6
28 dias

4,8

\subsubsection{Propiedades físicas}

Superficie específica Blaine (según $\mathrm{PCCH}-64$, apartado 2.2.) $3.061 \mathrm{~cm}^{2} / \mathrm{gr}$.

Peso específico real (según PCCH-64, apartado 2.3.) 2,99 $\mathrm{gr} / \mathrm{cm}^{3}$.

Expansión en autoclave (según PCCH-64, apartado 2.5.) 0,35\%.

Granulometría determinada mediante tamizadora Alpine por barrido de aire.

Retenido en tamiz de $\%$

tưz de malla (en y)

$\begin{array}{rr}200 & 0,1 \\ 120 & 0,9 \\ 90 & 3,0 \\ 60 & 10,6 \\ 40 & 19,4 \\ 33 & 32,1\end{array}$

Determinada mediante la pipeta de Andreasen

Tamaño (en $\mu)$

$\%$

$\begin{array}{rr}40 & 27,6 \\ 30 & 36,9 \\ 20 & 55,7 \\ 15 & 68,5 \\ 8 & 82,8\end{array}$

En la figura 2 representamos gráficamente la curva granulométrica de este cemento "ị".

\subsubsection{Propiedades mecánicas}

\section{Resistencias mecánicas}

El mortero realizado según PCCH-64. apartado 2.6., tiene un esparcimiento en la tabla de sacudidas del $76,5 \%$ y las siguientes resistencias mecánicas, expresadas en $\mathrm{kg} / \mathrm{cm}^{2}$.

\begin{tabular}{ccc} 
Edad & Flexotracción & Compresión \\
\hline 3 días & 55 & 211 \\
7 dias & 69 & 318 \\
28 dias & 83 & 453
\end{tabular}

14 
GRANULOMETRIA
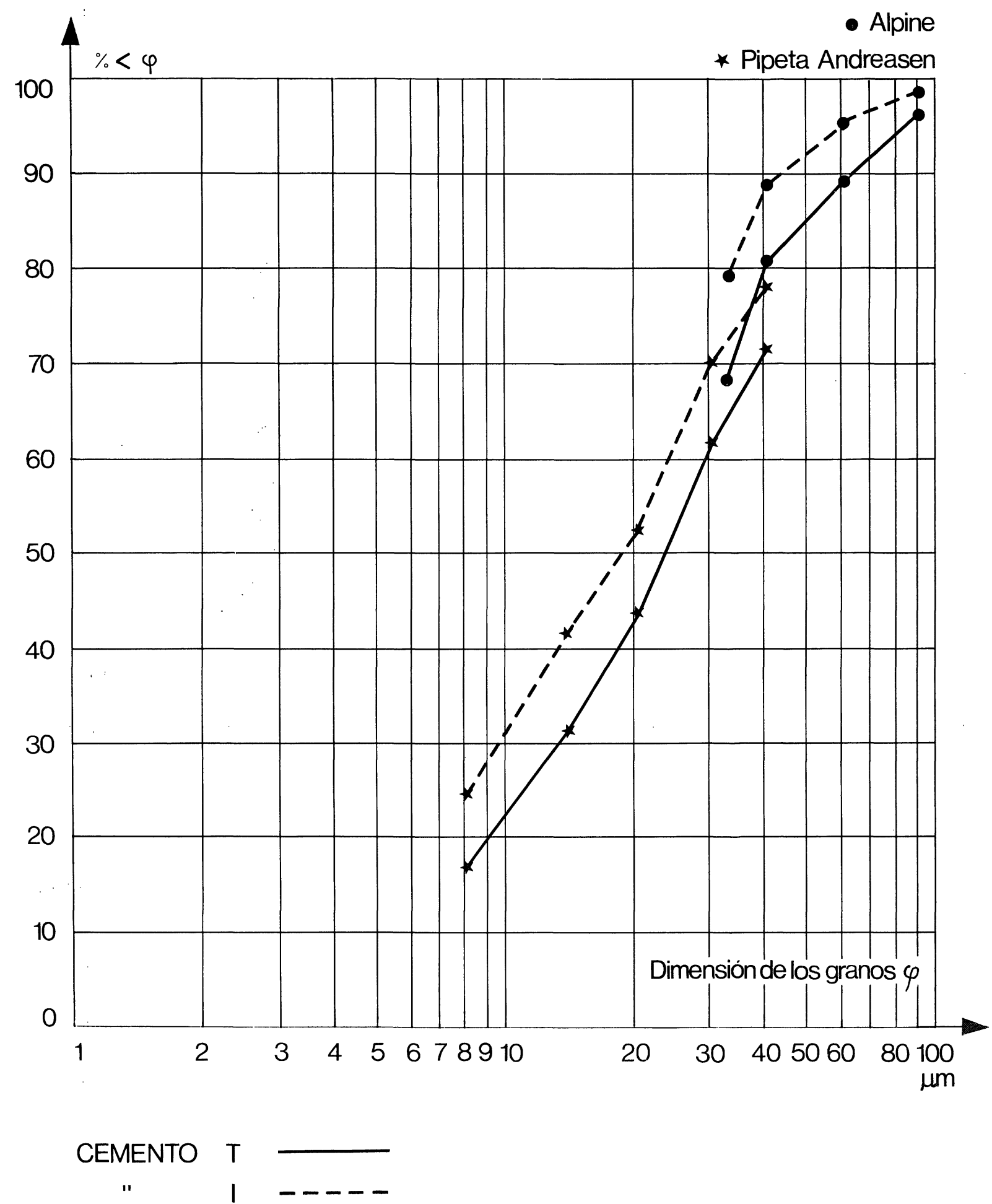

Fig. 2 


\section{FINALIDAD DEL ESTUDIO}

2.1. Obtener cementos de categoría resistente 350 , conteniendo aproximadamente el 20 y el $30 \%$ de cenizas volantes

A fin de poder mantener el nivel resistente a cortas edades, hemos molido el cemento descrito en el punto 1.2. (cemento $\mathrm{T}$ ) en el mismo molino de laboratorio en el que molimos las cenizas, hasta lograr el grado de finura que a continuación especificamos (cemento I).

Mediante tamizadora Alpine:

Tamiz (en $\mu)$ $\%$ Retenido

$\begin{array}{rr}200 & 0,1 \\ 120 & 0,3 \\ 90 & 1,3 \\ 60 & 4,4 \\ 40 & 11,5 \\ 33 & 20,3\end{array}$

Mediante pipeta de Andreasen:

Tamaño (en $\mu$ ) $\%$

$\begin{array}{rr}40 & 21,1 \\ 30 & 30,6 \\ 20 & 47,5 \\ 15 & 57,9 \\ 8 & 75,5\end{array}$

En la figura 2 representamos gráficamente la curva granulométrica de este cemento "I".

2.2. Conocer las propiedades de los cementos que se obtienen al adicionar una mayor proporción de una u otra ceniza, o una mezcla de ambas.

\section{CEMENTOS PREPARADOS}

Cemento I: Procede de la molturación en el molino de laboratorio del cemento de desig. nación $\mathrm{T}$.

Cemento II: Constituido por el $90 \%$ del cemento T y $10 \%$ de cenizas de Puentes molidas.

Cemento III: Constituido por el $80 \%$ de cemento I y $20 \%$ de cenizas de Puentes molidas.

Cemento IV: Constituido por el $90 \%$ de cemento I y $10 \%$ de cenizas de Ponferrada molidas.

Cemento V: Constituido por el $80 \%$ de cemento I y $20 \%$ de cenizas de Ponferrada molidas.

Cemento VI: Constituido por el $80 \%$ de cemento I, $10 \%$ de cenizas de Puentes molidas y $10 \%$ de cenizas de Ponferrada molidas.

16 


\section{ENSAYOS REALIZADOS}

Los valores que a continuación exponemos son media de 10 ensayos de muestras distintas.

4.1. Análisis químico (según PCCH-64, apartado 2.7.)

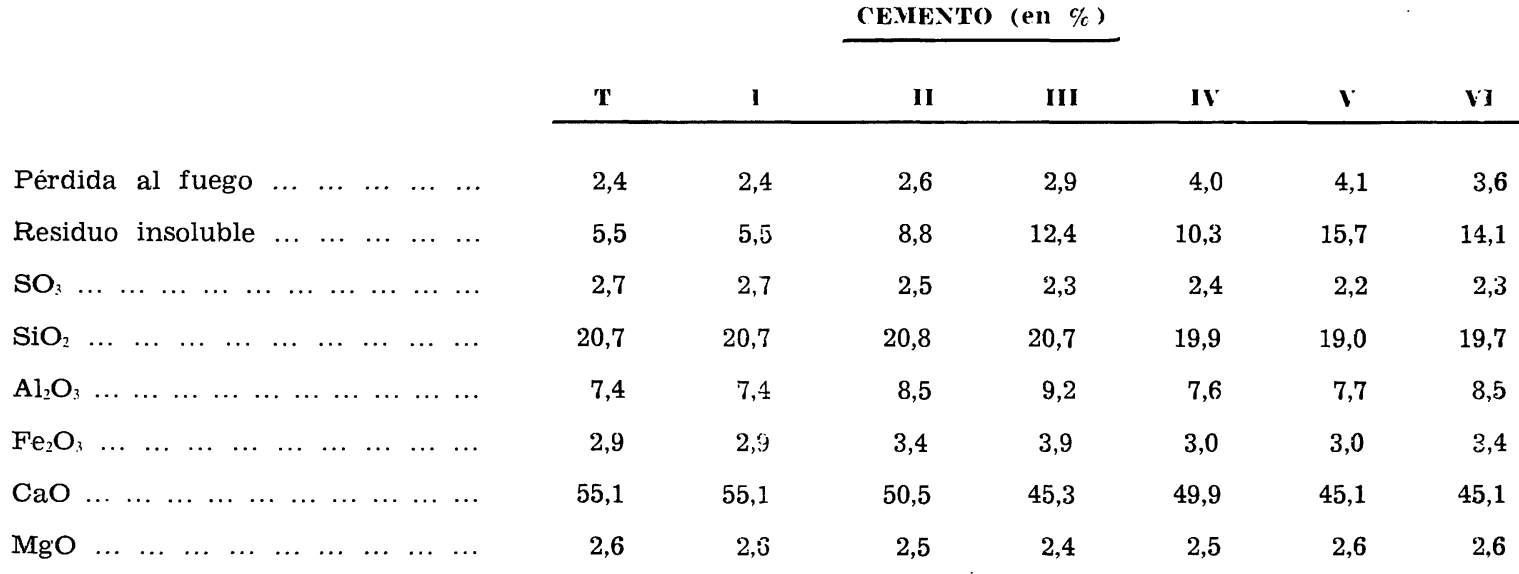

\subsection{Valor puzolánico}

4.2.1. Ensayo a $40^{\circ} \mathrm{C}$. Valores expresados en milimoles/litro

I IIAS

28 IIA

\begin{tabular}{ccccc}
\hline Cemento & Ncalinidad total & Cao & Nlcalinidad total & Cao \\
\hline T & 67,8 & 7,6 & 71,7 & 4,8 \\
I & 70,4 & 7,7 & 74,5 & 4,8 \\
II & 62,4 & 5,3 & 70,9 & 4,4 \\
III & 57,5 & 4,2 & 57,8 & 1,8 \\
IV & 63,3 & 5,9 & 78,0 & 4,0 \\
V & 62,2 & 5,0 & 75,5 & 2,2
\end{tabular}

Estos valores se representan en el gráfico de la figura 3.

Los cementos $\mathrm{T}$ y I son puzolánicos a 28 días (recuérdese que ya contienen una adición de cenizas volantes de aproximadamente el $10 \%$ ). La adición de mayor cantidad de cenizas confiere a todos los cementos propiedades puzolánicas ya a la edad de 7 días.

Para un porcentaje de adición igual, las cenizas de Puentes aportan al cemento una puzolanicidad mayor que las cenizas de Ponferrada.

4.2.2. Además de realizar este ensayo, hemos creído interesante conocer el comportamiento puzolánico de estos cementos a otras temperaturas $\left(20^{\circ} \mathrm{C}\right.$ y temperatura ambiente) y a edades superiores (90 y 180 días 6 meses y 1 año). 


\section{ENSAYO DE PUZOLANICIDAD SEGUN FRATINI}

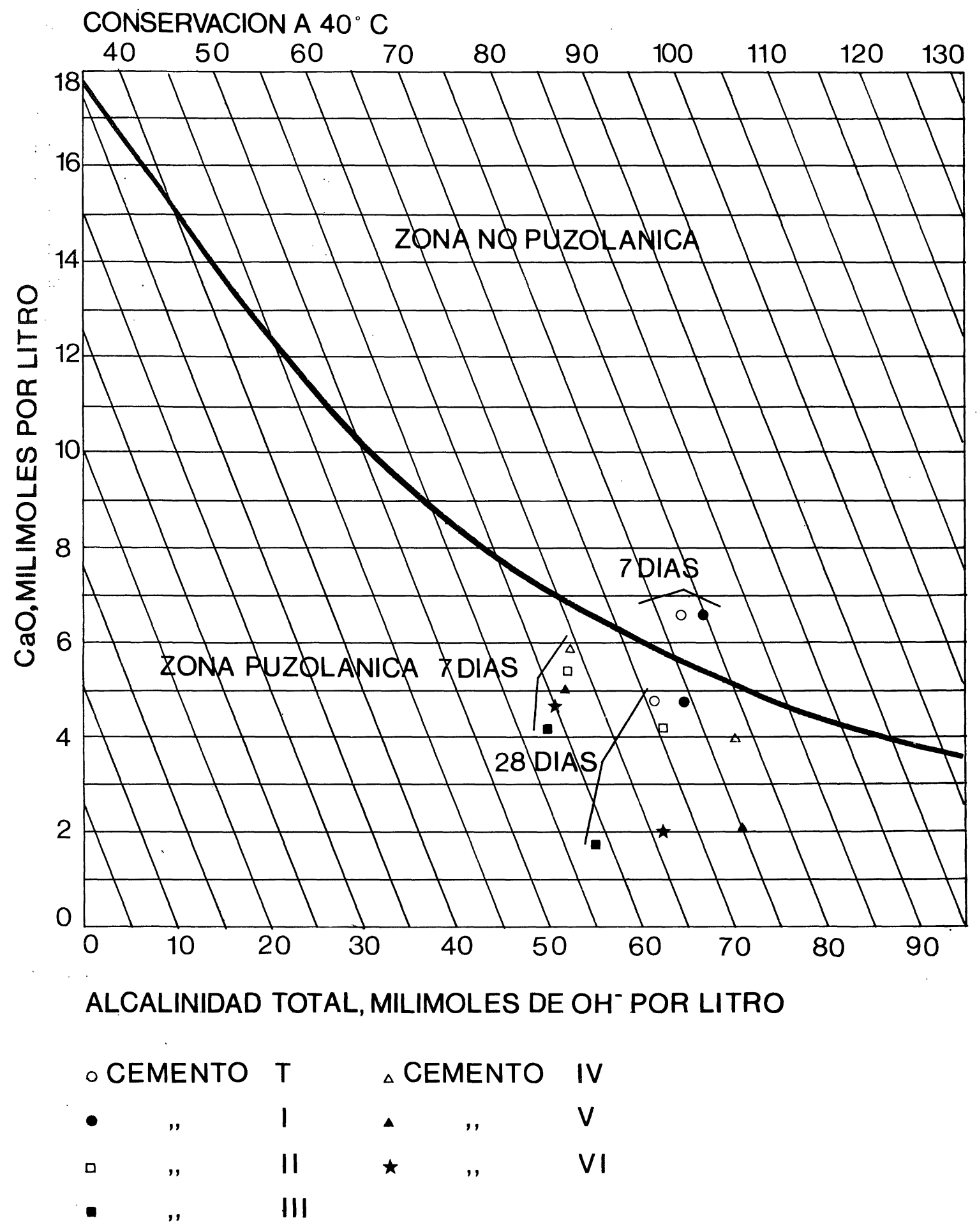

Fig. 3 


\subsubsection{Ensayo a $20^{\circ} \mathrm{C}$}

Los Erlenmeyer se conservaron en la cámara de curado de probetas hasta la edad del ensayo. Valores expresados en milimoles/litro.

90 DIAS

180 DIAS

1 ANO

\begin{tabular}{|c|c|c|c|c|c|c|}
\hline Cemento & Alcalinidad total & $\mathbf{C a O}$ & Alcalinidad total & CaO & Alcalinidad total & CaO \\
\hline $\mathbf{T}$ & 76,1 & 6,6 & 79,1 & 6,0 & 83,8 & 5,5 \\
\hline I & 77,9 & 6,4 & 80,9 & 5,9 & 83,9 & 5,8 \\
\hline II & 73,3 & 6,2 & 76.0 & 6,0 & 79,3 & 5,9 \\
\hline III & 66,3 & 5,3 & 65,5 & 3,7 & 60,7 & 1,4 \\
\hline IV & 76,2 & 5,9 & 82,9 & 5,4 & 88,3 & 4,5 \\
\hline $\mathbf{V}$ & 74,4 & 5,4 & 82,6 & 4,5 & 83,2 & 1,3 \\
\hline VI & 69,9 & 5,6 & 73,0 & 3,9 & 69,5 & 1,2 \\
\hline
\end{tabular}

Representamos estos puntos en el diagrama de las figuras 4 y 5 .

A esta temperatura son puzolánicos, ya a la edad de 90 días, los cementos III, V y VI, que se prepararon sustituyendo el $20 \%$ del cemento I por cenizas volantes de Puentes, Ponferrada o una mezcla de ambas en igual proporción, respectivamente.

4.2.2.2. Ensayo a temperatura ambiente

Los Erlenmeyer se conservaron en un recipiente en el jardín del laboratorio hasta la edad del esayo.

\begin{tabular}{ccccccc} 
& 9 90 DIAS & \multicolumn{1}{c}{ 180 DIAS } & \multicolumn{1}{c}{ ANO } \\
\hline Cemento & Alcalinidad total & CaO & Alcallnidad total & CaO & Alcalinidad total & CaO \\
\hline T & 78,4 & 10,7 & 78,2 & 7,6 & 81,9 & 6,6 \\
I & 81,1 & 10,2 & 79,8 & 7,5 & 81,2 & 6,3 \\
II & 69,6 & 7,2 & 72,8 & 6,5 & 76,7 & 6,5 \\
III & 62,4 & 6,3 & 64,7 & 5,1 & 63,3 & 3,3 \\
IV & 75,8 & 9,4 & 76,5 & 6,4 & 83,6 & 5,6 \\
V & 70,6 & 8,3 & 74,0 & 6,1 & 82,8 & 4,5 \\
VI & 64,6 & 6,7 & 68,9 & 5,9 & 71,2 & 3,5
\end{tabular}

Representamos estos valores en el diagrama de la figura 6.

A la temperatura ambiente sólo son puzolániicos a estas edades los cementos III (80\% de cemento I y $20 \%$ de cenizas de Puentes molidas) y el VI ( $80 \%$ de cemento I y $20 \%$ de una mezcla a partes iguales de cenizas de Puentes y de Ponferrada).

Los cementos obtenidos por sustitución del $20 \%$ de cemento I por cenizas de Ponferrada, no son puzolánicos hasta la edad de 1 año. 


\section{ENSAYO DE PUZOLANICIDAD SEGUN FRATINI}

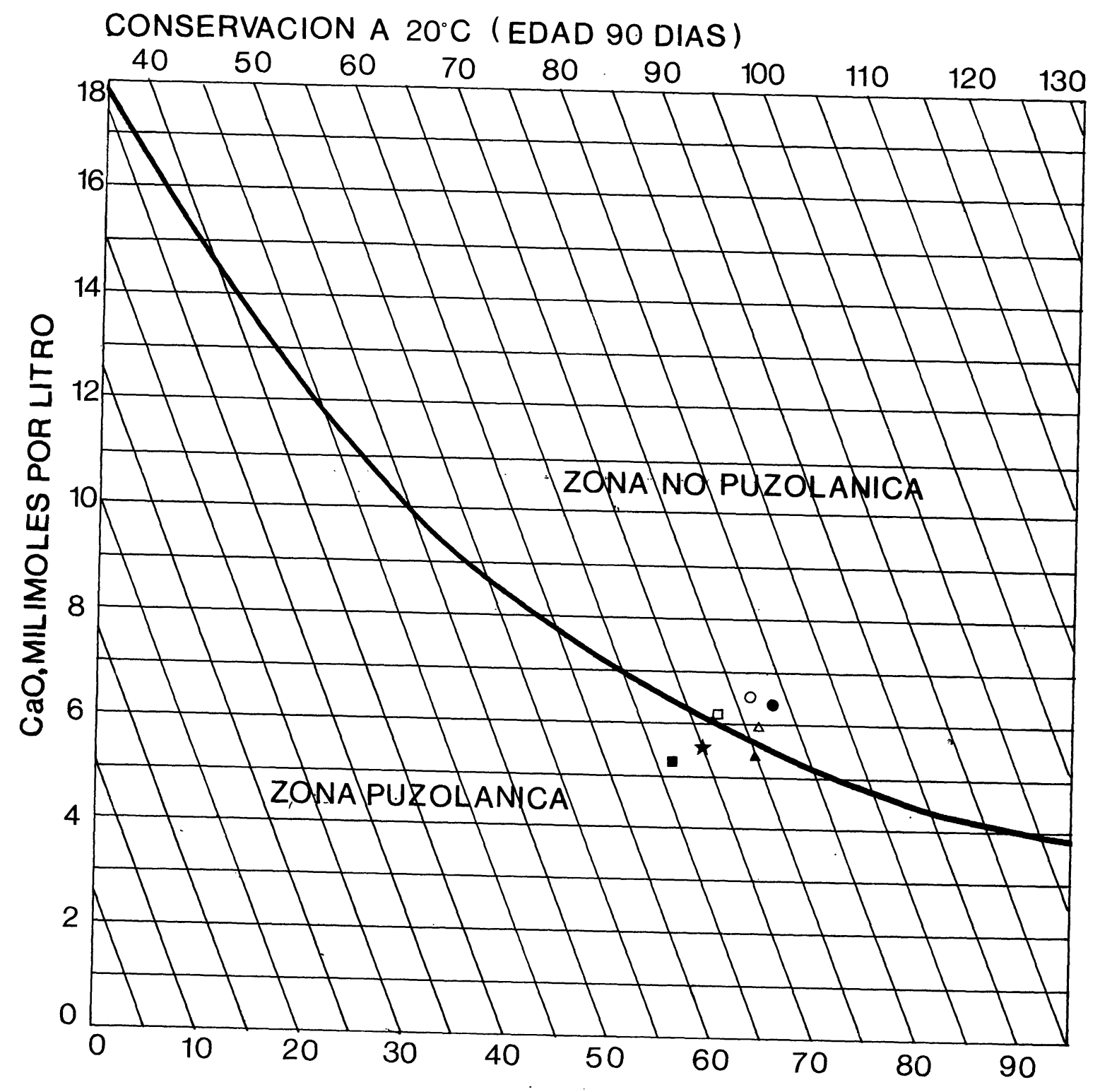

ALCALINIDAD TOTAL, MILIMOLES DE OH POR LITRO

$\begin{array}{cccccc}\triangle \text { CEMENTO } & \mathrm{T} & & \triangle \\ \bullet & \text { CEMENTO } & \mathrm{IV} \\ \square & \mathrm{I} & \star & , & \mathrm{V} \\ - & \mathrm{II} & \star & , & \mathrm{VI}\end{array}$




\section{ENSAYO DE PUZOLANICIDAD SEGUN FRATINI}

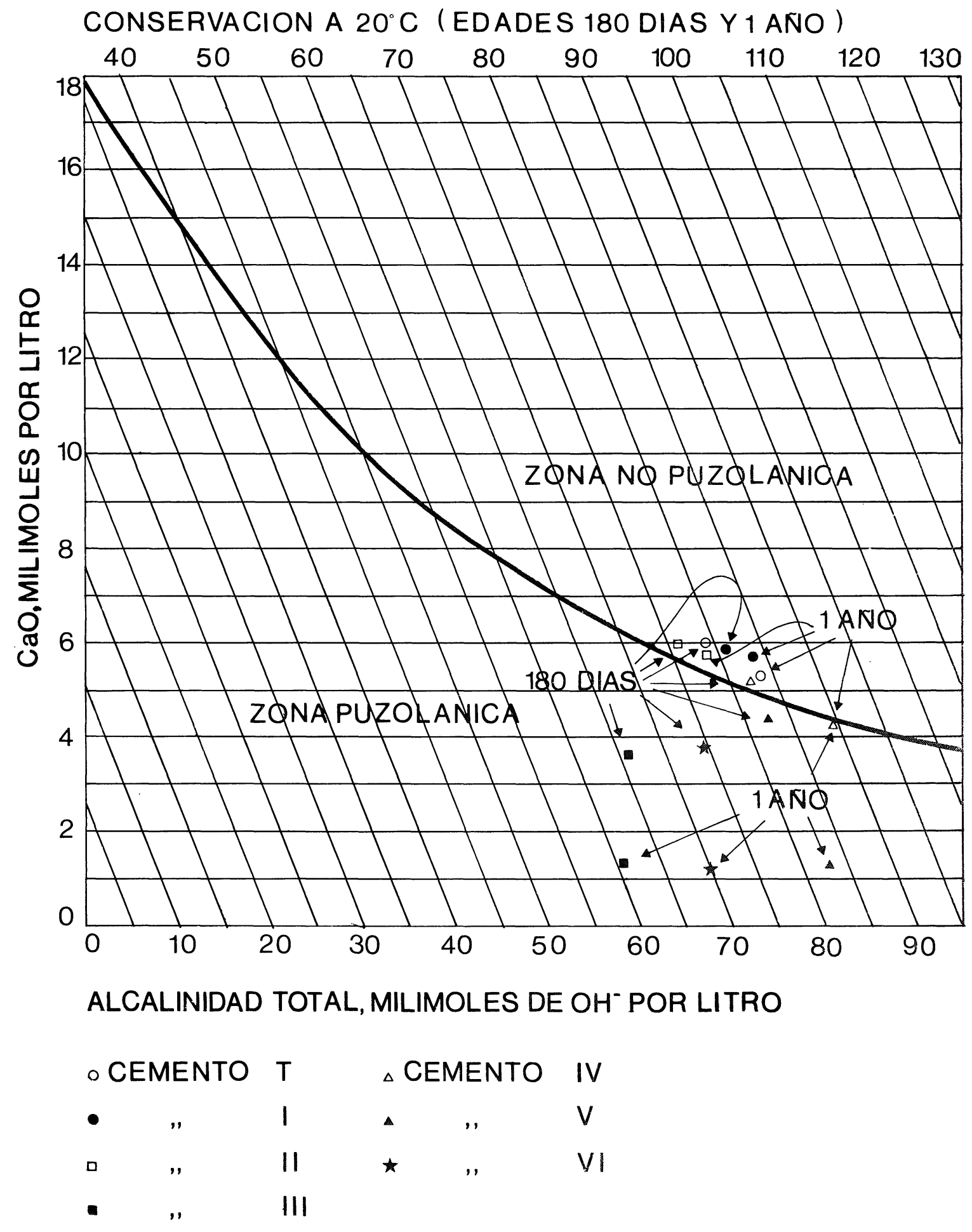

Fig. : 


\section{ENSAYO DE PUZOLANICIDAD SEGUN FRATINI}

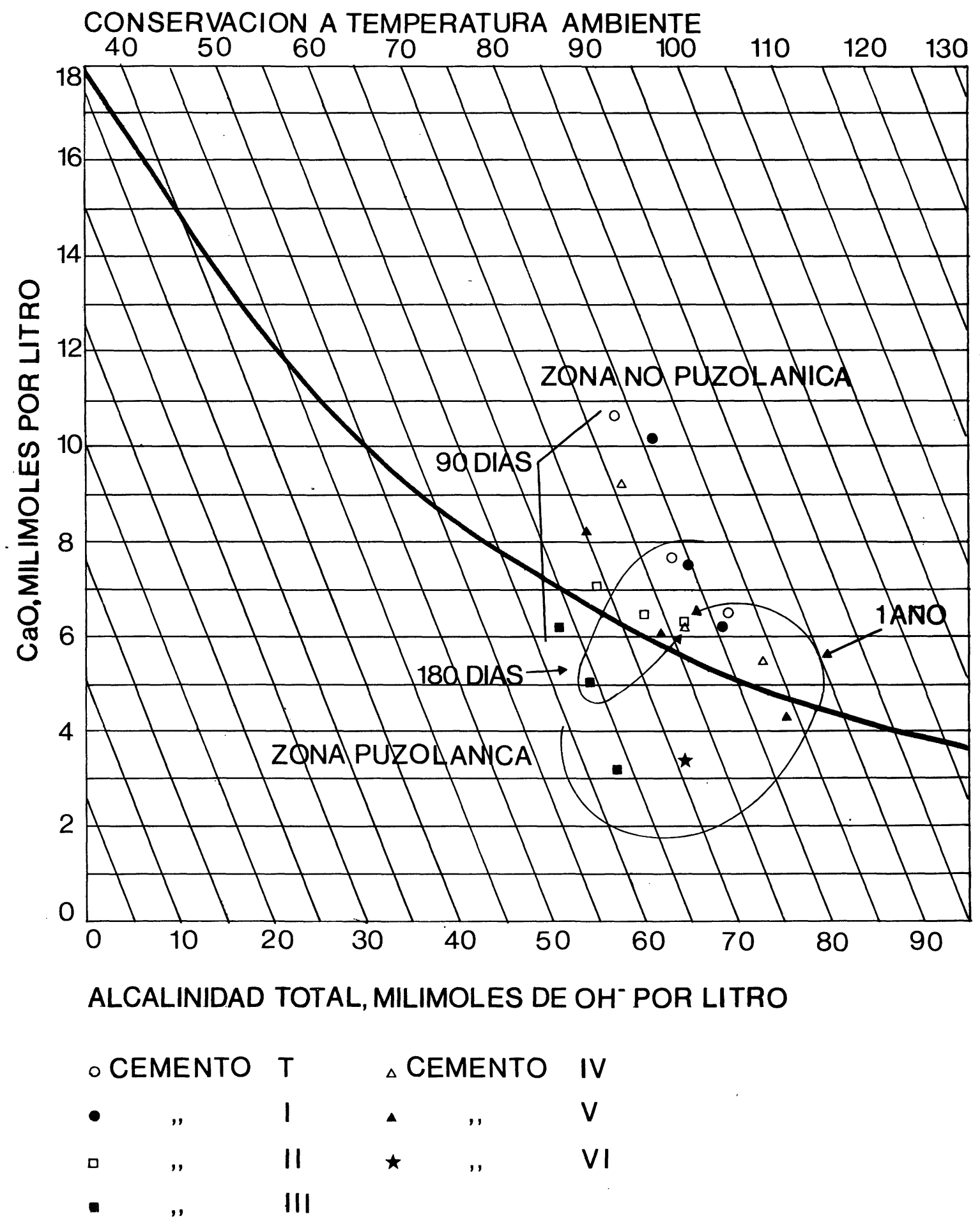

Fig. 6 


\subsubsection{Método propuesto por Lea en su libro "Química del cemento y del hormigón".}

Consiste en determinar la diferencia de la aceleración del endurecimiento en función del aumento de la temperatura del agua (entre 20 y $50^{\circ} \mathrm{C}$ ).

A la edad de 7 días se ensayan a flexotracción y compresión probetas de morteros de los distintos cementos, curadas en agua a $20^{\circ} \mathrm{C}$, y otras curadas 5 días en agua a $20^{\circ} \mathrm{C}$ y 2 días en agua a 50: C. Expresamos los resultados obtenidos en $\mathrm{kg} / \mathrm{cm}^{2}$.

\begin{tabular}{|c|c|c|c|}
\hline Cemento & Agua a $20^{\circ} \mathrm{C}$ & $\begin{array}{l}\text { 5 días agua } 20 \circ \mathrm{C} \\
2 \text { dias agua } 50^{\circ} \mathrm{C}\end{array}$ & Diferencias \\
\hline
\end{tabular}

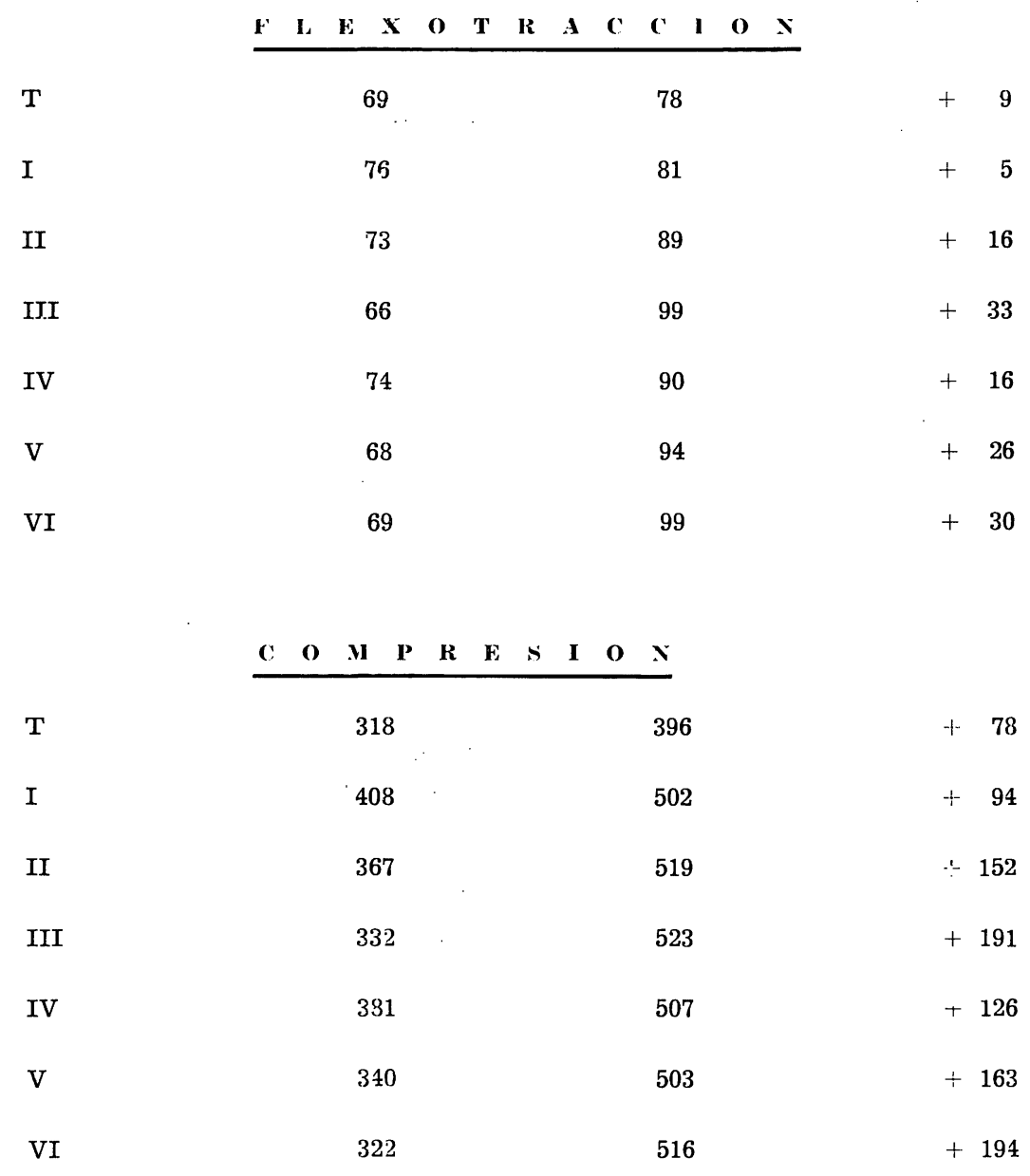

Las cenizas de Puentes aportan al cemento un valor puzolánico más alto que las de Ponferrada, según métodos de Fratini y Lea. Cuanto mayor es el contenido de cenizas volantes, más alto es el valor puzolánico del cemento.

\subsection{Propiedades físicas}

\subsubsection{Granulometría}

Resultados obtenidos al realizar el ensayo en la tamizadora Alpine por barrido de aire. 


\begin{tabular}{|c|c|c|c|c|c|c|c|}
\hline & $\mathbf{T}$ & 1 & 11 & III & IV & $v$ & VI \\
\hline 200 & 0,1 & 0,1 & 0,1 & 0,2 & 0,1 & 0,1 & 0,2 \\
\hline 90 & 3,0 & 1,3 & 1,6 & 1,6 & 1,0 & 0,9 & 1,5 \\
\hline 60 & 10,6 & 4,4 & 5,4 & 4,7 & 3,7 & 3,3 & 4,3 \\
\hline 40 & 19,4 & 11,5 & 12,1 & 11,4 & 9,6 & 8,8 & 10,8 \\
\hline
\end{tabular}

Ensayo realizado mediante la pipeta de Andreasen.

\begin{tabular}{crrrrrrr} 
Tamaño & T & I & II & III & IV & V & VI \\
\hline 40 & 27,6 & 21,1 & 18,7 & 19,8 & 17,8 & 18,4 & 19,1 \\
30 & 36,9 & 30,6 & 27,8 & 28,7 & 27,7 & 27,4 & 28,7 \\
20 & 55,7 & 47,5 & 46,7 & 47,7 & 46,3 & 47,8 & 47,0 \\
15 & 68,5 & 57,9 & 58,1 & 59,1 & 58,9 & 59,2 & 60,0 \\
8 & 82,8 & 75,5 & 76,5 & 76,0 & 77,7 & 79,9 & 75,4
\end{tabular}

En la figura 7 representamos estas granulometrías. Las curvas granulométricas de los cementos I, II, III, IV, V y VI están situadas dentro de la zona rayada.

Como se puede observar, las granulometrías de los cementos que constituyen este estudio están incluidas en una gama de valores muy estrecha.

4.3.2. Peso específico real (según PCCH-64, apartado 2.3.)

$\begin{array}{ll}\text { T } & 2,99 \\ \text { I } & 3,01 \\ \text { II } & 2,96 \\ \text { III } & 2,90 \\ \text { IV } & 2,94 \\ \text { V } & 2,88 \\ \text { VI } & 2,89\end{array}$


GRANULOMETRIA

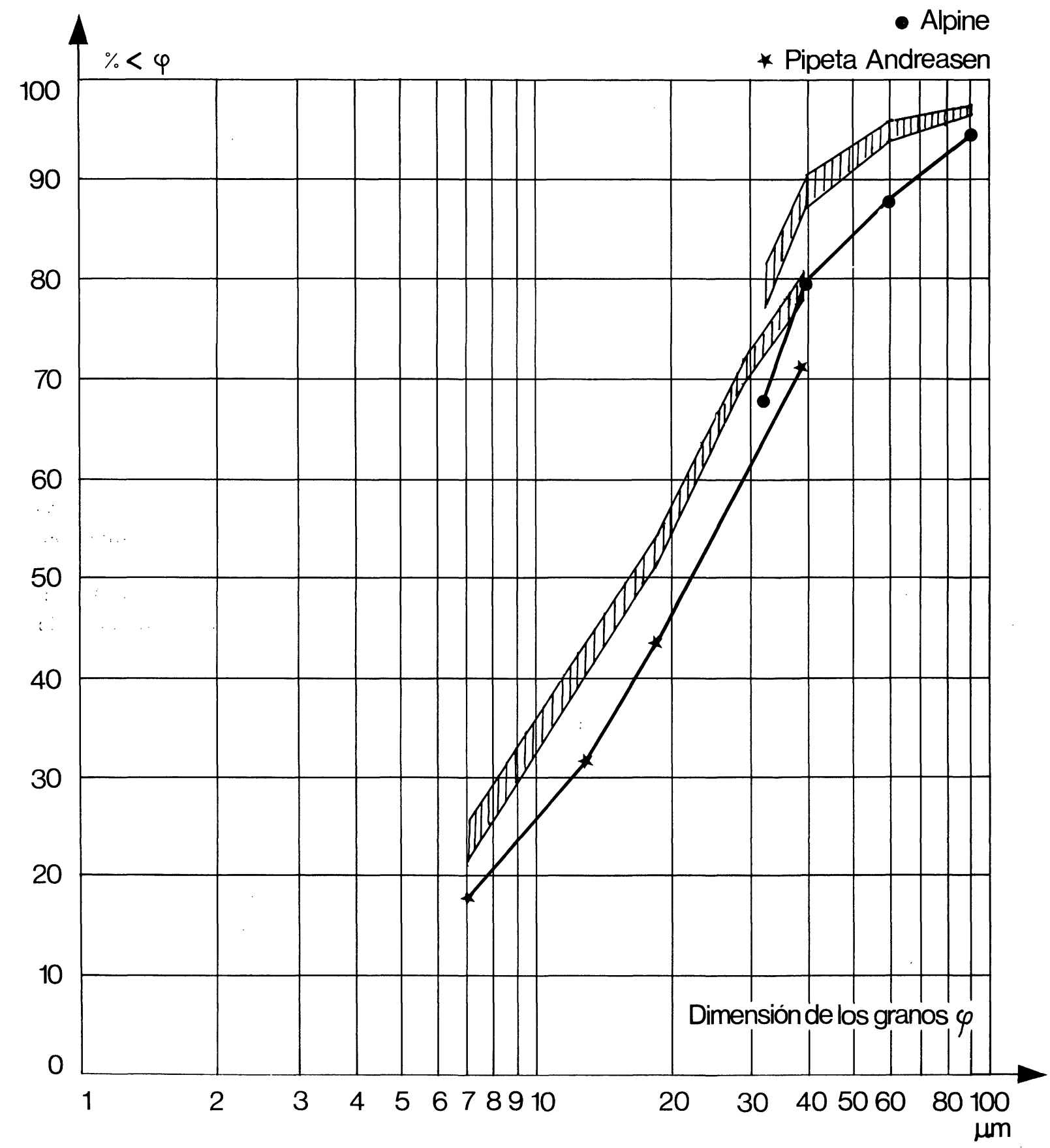

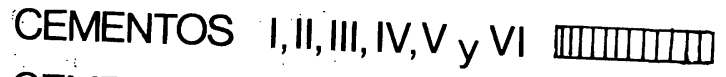
CEMENTO $T$.

Flg. 7 
La determinación de la superficie específica Blaine se ha realizado teniendo en consideración el peso específico real.

La porosidad, en todos los casos 0,5 .

\begin{tabular}{cc} 
Cemento & $\mathbf{c m} \mathbf{m}^{2 / \mathbf{g r}}$ \\
\hline T & 3.061 \\
I & 4.709 \\
II & 5078 \\
III & 6.138 \\
IV & 4.480 \\
V & 4.018 \\
VI & 4.719
\end{tabular}

Las cenizas de Puentes aumentan notablemente el Blaine.

Probablemente la forma y superficie de los gránulos de las cenizas volantes (ver punto 1.1.1.) influye en la permeabilidad al aire, al igual que en la cantidad de agua de amasado.

Sólo la diferencia de las granulometrías (ver apartado 1.1.5. y gráfico de la figura 1), quizás no justifique por sí sola estas diferencias que se observan en los valores Blaine y la cantidad de agua de amasado para obtener un mismo esparcimiento.

4.3.4. Expansión en autoclave (según PCCH-64, apartado 2.5.)

\begin{tabular}{ll} 
Cemento & $\%$ \\
\hline T & 0,35 \\
I & 0,25 \\
II & 0,15 \\
III & 0,11 \\
IV & 0,15 \\
V & 0,13 \\
VI & 0,12
\end{tabular}

4.3.4.1. El cemento $\mathrm{T}$ después de molido (cemento $\mathrm{I}$ ), presenta una menor expansión en autoclave. Probablemente porque eventuales nódulos de cal libre reaccionan con el agua de amasado antes del fraguado del cemento y también porque el aumento de finura de la ceniza, que ya contiene el cemento $\mathrm{T}$ (aproximadamente un $10 \%$ ), trae consigo un mayor efecto puzolánico (ver gráfico de la figura 3 ).

4.3.4.2. La adición de cenizas proporciona a los cementos una mayor estabilidad. 


\subsection{Ensayos mecánicos}

\subsubsection{Preparación de morteros}

Los morteros de estos cementos se prepararon ateniéndose en todo a la norma PCCH-64, apartado 2.6., excepto en lo que se refiere al agua de amasado, que se añadió en la cantidad suficiente para lograr en cada caso ur esparcimiento análogo $(76,5 \%)$ al obtenido con el mortero de cemento $\mathrm{T}$ y relación agua/cemento $=0,5$ (ver punto 1.2.4.).

Las relaciones agua/cemento necesarias han sido:

\begin{tabular}{ll} 
Cemento & \\
\hline I & 0,485 \\
JI & 0,501 \\
III & 0,519 \\
IV & 0,475 \\
V & 0,463 \\
VI & 0,490
\end{tabular}

No hemos operado a relación agua/cemento constante (igual a 0,5) a fin de tener en cuenta el efecto que el cambio de finura y la adición de una $u$ otra ceniza puede tener en la cantidad de agua de amasado necesaria para lograr el mismo esparcimiento.

Las cenizas de Ponferrada disminuyen el agua de amasado para un mismo esparcimiento. Las cenizas de Puentes aumentan la cantidad de agua.

4.4.1.1. Se determinó la exudación, al cabo de las dos horas, de todos los morteros siguiendo el método que M. Venuat describe en su trabajo "De l'étude du comportement rhéologique de quelques cendres volantes" (Revue des Matériaux de Construction n. ${ }^{\circ}$ 615). Se han utilizado recipientes cilíndricos de $5 \mathrm{~cm}$ de diámetro y $20 \mathrm{~cm}$ de altura.

El mortero de cemento T (realizado según PCCH-64, apartado 2.6.) tiene una exudación de 2,5 gr.

Los morteros a que nos referimos en el punto 4.4.1. presentan todos ellos una exudación inferior al $50 \%$ del valor del mortero de cemento $\mathrm{T}$.

4.4.1.2. Hemos preparado un total de 270 probetas de cada uno de los cementos, distribuidas en las diferentes condiciones que a continuación exponemos (10 probetas a cada edad y para çada condición).

\subsubsection{Condiciones de curado y conservación}

Conservamos probetas en cuatro condiciones:

4.4.2.1. Água a $200^{\circ} \mathrm{C}$ (según norma)

\subsubsection{Temperatura ambiente}

Las probetas a las 24 horas se desenmoldaron y colocaron sobre la hierba del jardín del laboratorio hasta la edad del ensayo. 
Las probetas sufren todas las variaciones climatológicas (temperatura, lluvia, sol y nieve de nuestra región; en un lugar a $600 \mathrm{~m}$ de altura sobre el nivel del mar).

Antes del ensayo a flexotracción y compresión las probetas se sumergen en agua durarte 24 horas.

4.4.2.3. Probetas conservadas en un recipiente que contiene una disolución de $\mathrm{SO}_{1} \mathrm{Mg}$ en agua con una concentración del $5 \%$ :

a) situado en el interior de la cámara de conservación de probetas a $20^{\circ} \mathrm{C}$.

b) Situado en el exterior del laboratorio a temperatura ambiente.

\subsubsection{Edades del ensayo}

De todos los cementos se conservaron probetas para ensayar a las edades de $3,7,28,90$ y 180 días y $1,2,3$ y 4 años en los medios de conservación de agua a $20 \mathrm{C}$ y aire a tempera. tura ambiente.

En $\mathrm{SO}_{4} \mathrm{Mg}$ a $20^{\circ} \mathrm{C}$ se conservaron probetas para ensayar a las edades de 180 días, $1,2,3$ y 4 años. En $\mathrm{SO}_{4} \mathrm{Mg}$ a temperatura ambiente, las edades de ensayo han sido 2, 3 y 4 años.

\subsubsection{Resultados}

Los valores indicados para cada cemento, a cada edad y medio de conservación, son media de 10 ensayos. Expresados en $\mathrm{kg} / \mathrm{cm}^{2}$.

4.4.4.1. Conservación en agua a $20^{\circ} \mathrm{C}$

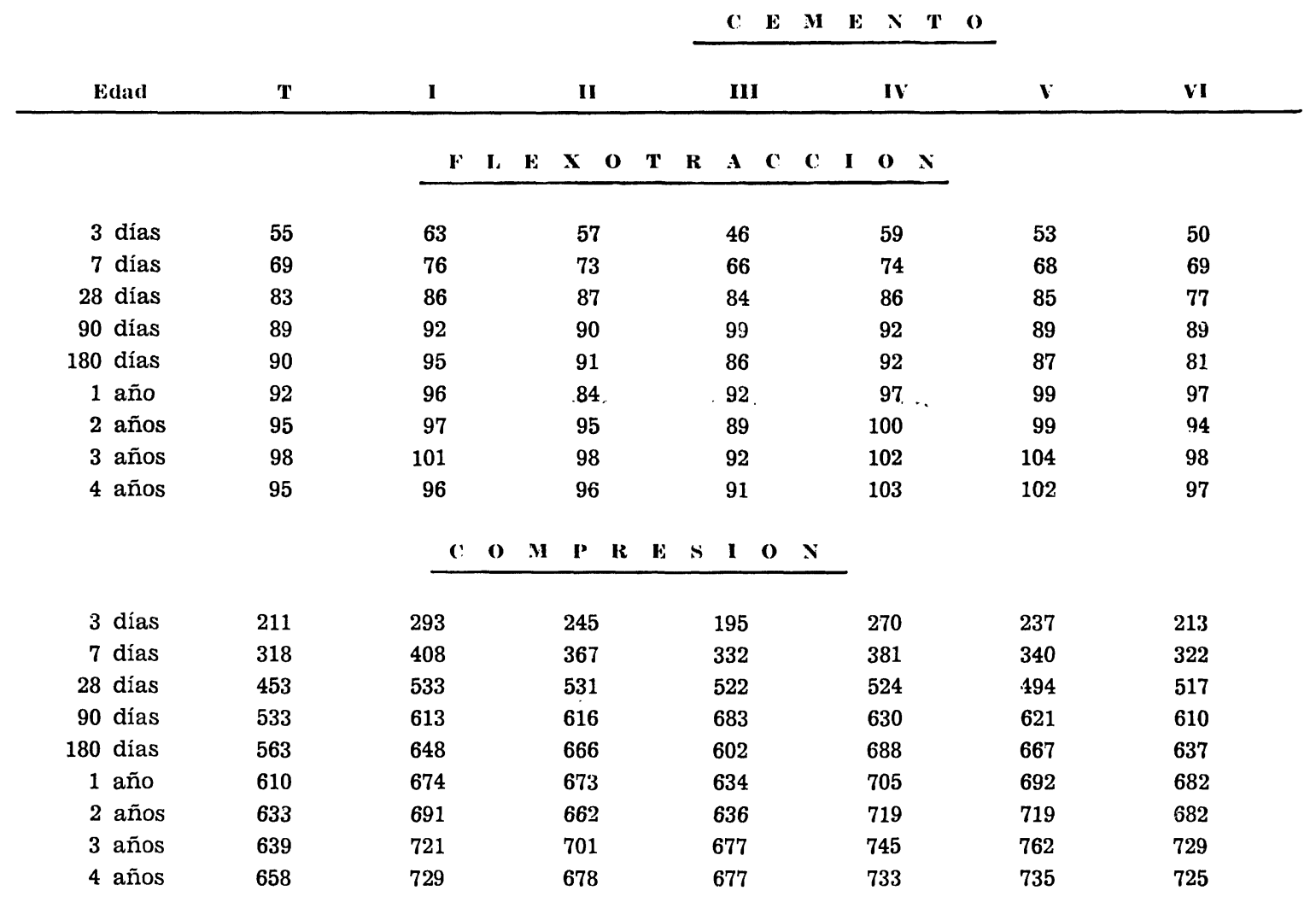


4.4.4.2. Medio de conservación, aire a temperatura ambiente

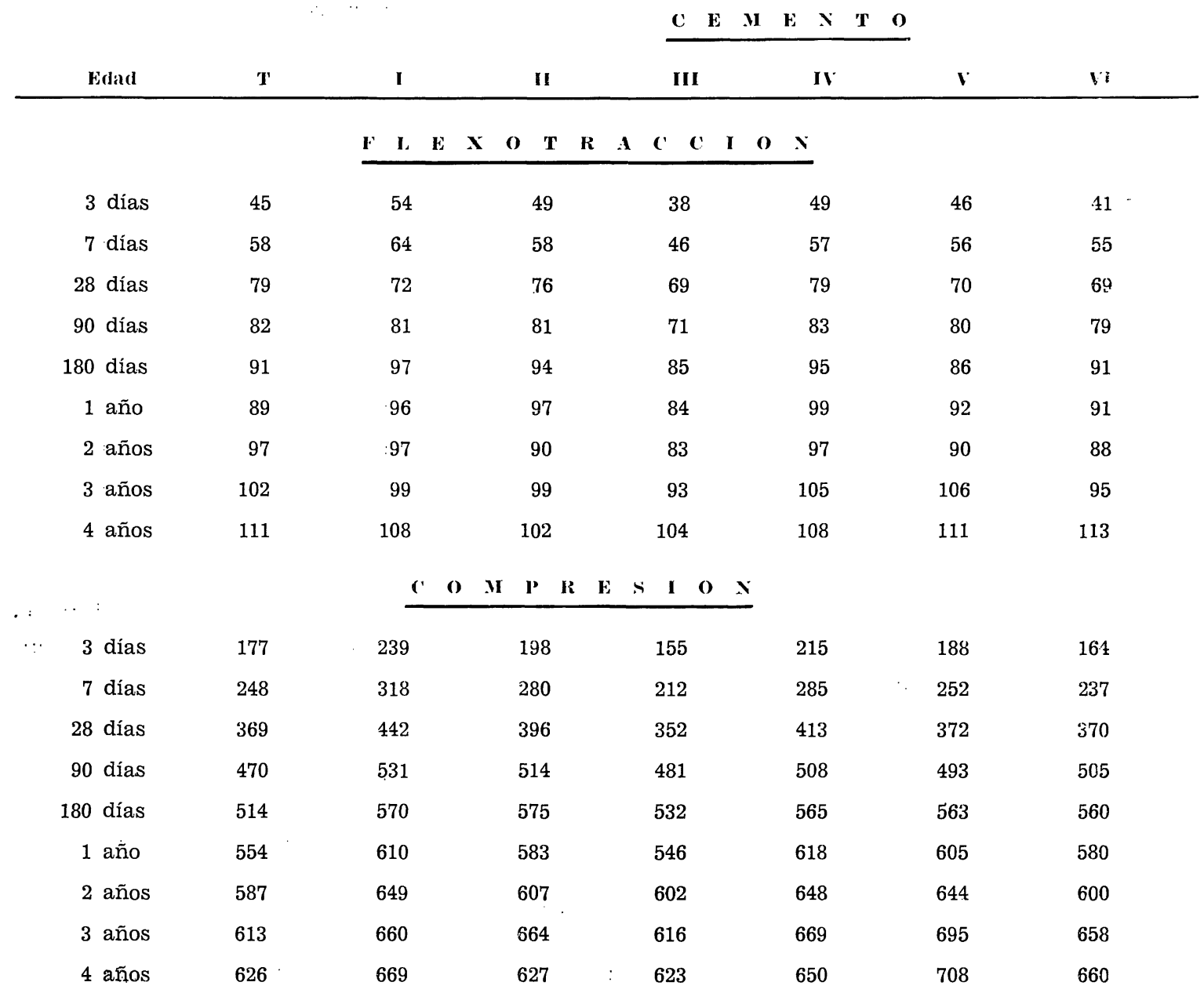

4.4.4.3. Medio de conservación, $\mathrm{SO}_{4} \mathrm{Mg}$ a $20^{\circ} \mathrm{C}$

\begin{tabular}{lllllll}
$\mathbf{C}$ & $\mathbf{E}$ & $\mathbf{H}$ & $\mathbf{E}$ & $\mathbf{N}$ & $\mathbf{T}$ & $\mathbf{O}$ \\
\hline
\end{tabular}

\begin{tabular}{lllllllll} 
Edad & T & I & II & III & IV & V & VI \\
\hline
\end{tabular}

\begin{tabular}{lllllllllllll}
$\mathbf{F}$ & $\mathbf{L}$ & $\mathbf{E}$ & $\mathbf{X}$ & $\mathbf{O}$ & $\mathbf{T}$ & $\mathbf{R}$ & $\boldsymbol{A}$ & $\mathbf{C}$ & $\mathbf{C}$ & $\mathbf{I}$ & $\mathbf{O}$ & $\mathbf{N}$ \\
\hline
\end{tabular}

$\begin{array}{crrrrrrr}180 \text { dias } & 96 & 107 & 103 & 108 & 116 & 114 & 108 \\ 1 \text { año } & 62 & 100 & 102 & 110 & 104 & 113 & 115 \\ 2 \text { años } & 12 & 57 & 82 & 112 & 96 & 106 & 108 \\ 3 \text { años } & 3 & 21 & 64 & 99 & 84 & 105 & 97 \\ 4 \text { años } & 0 & 9 & 51 & 84 & 63 & 89 & 88\end{array}$

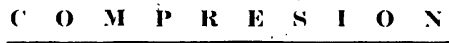

$\begin{array}{crrrrrrr}180 \text { días } & 556 & 617 & 647 & 607 & 660 & 659 & 627 \\ 1 \text { año } & 526 & 622 & 632 & 581 & 676 & 652 & 633 \\ 2 \text { años } & 242 & 537 & 584 & 534 & 640 & 644 & 600 \\ 3 \text { años } & 77 & 311 & 545 & 474 & 594 & 616 & 543 \\ 4 \text { años } & 0 & 192 & 423 & 361 & 508 & 522 & 427\end{array}$


4.4.4.4. Medio de conservación, $\mathrm{SO}_{4} \mathrm{Mg}$ a temperatura ambiente

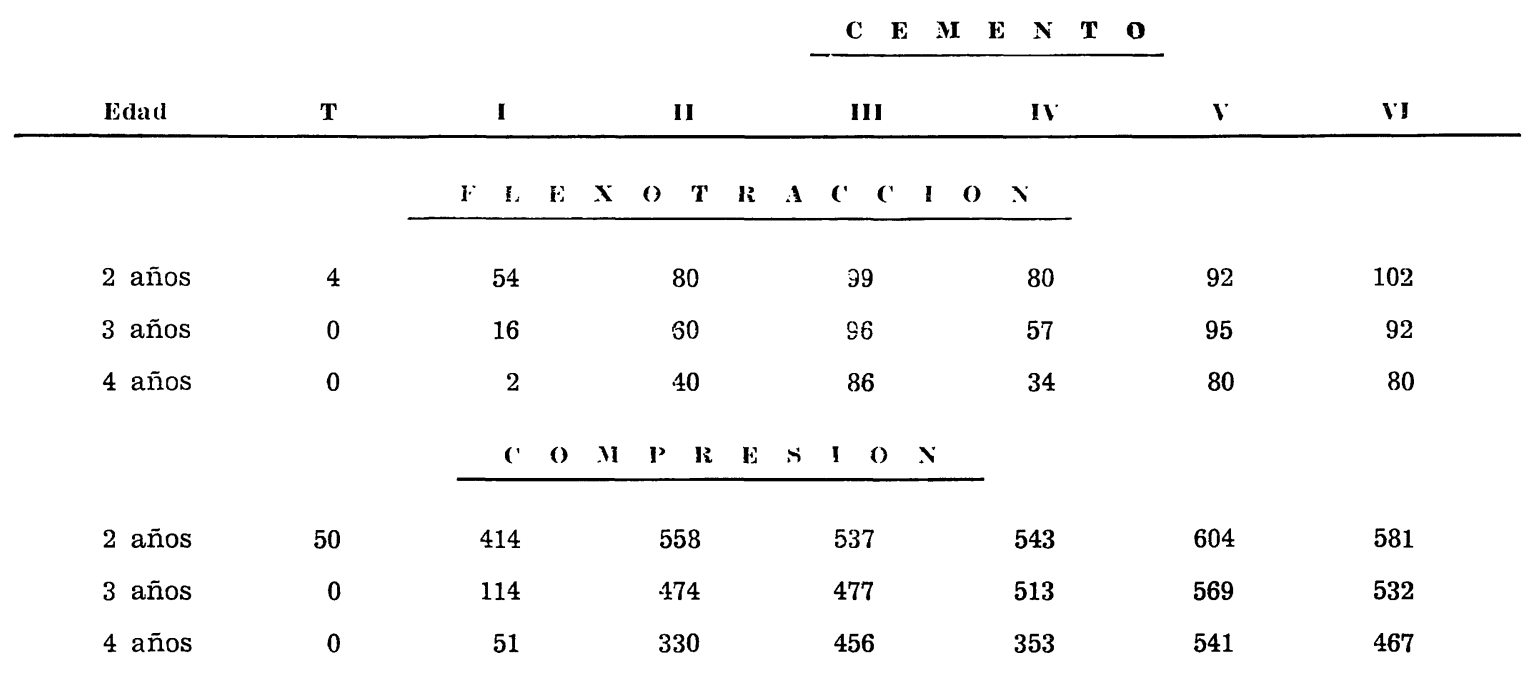

4.4.5. Si damos el valor 1 a las resistencias del cemento $\mathrm{T}, \mathrm{y}$ si referimos las resistencias a compresión de los distintos cementos a cada edad y en cada condición a las correspondientes del cemeno $\mathrm{T}$, obtendremos la siguiente tabla:

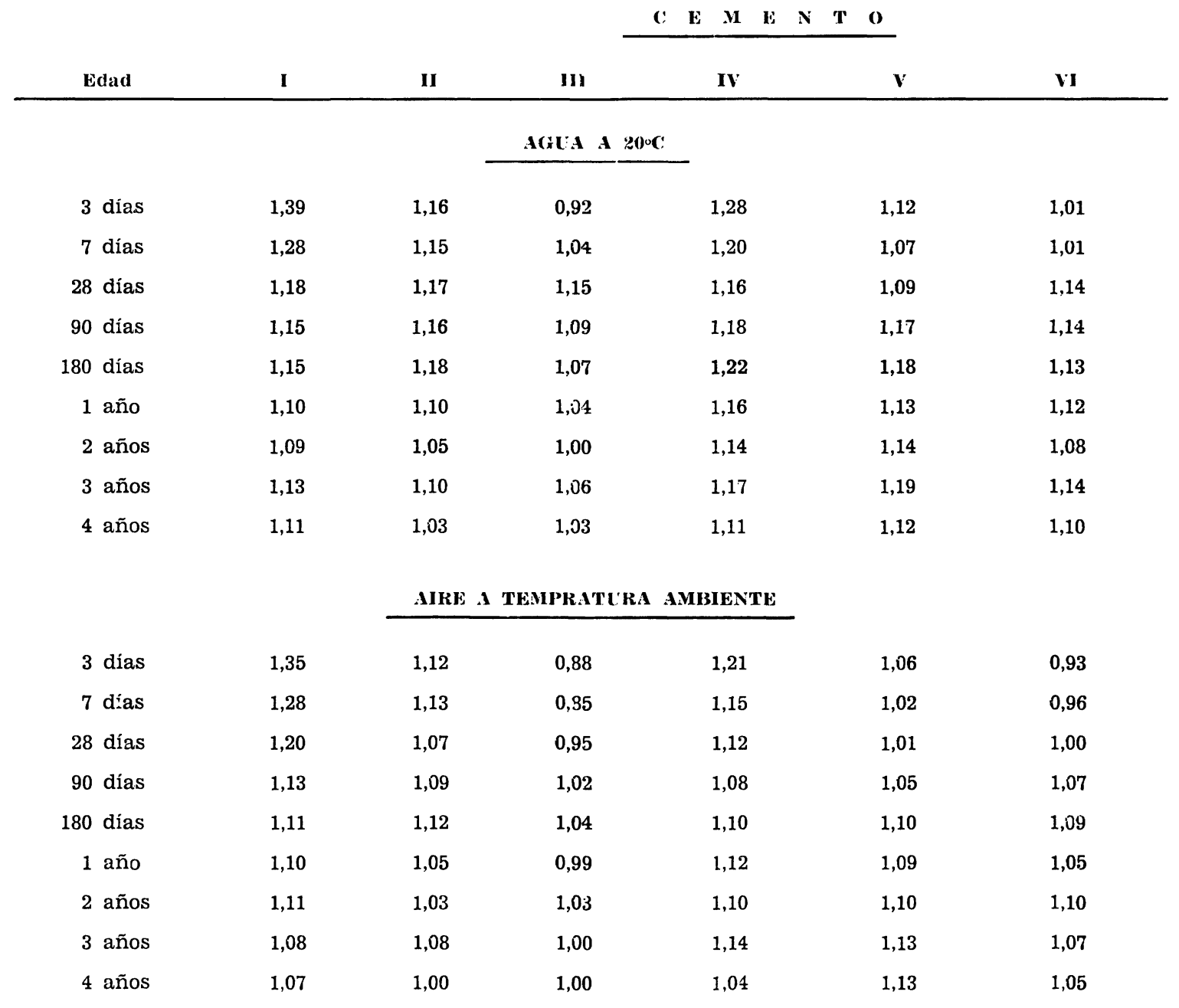




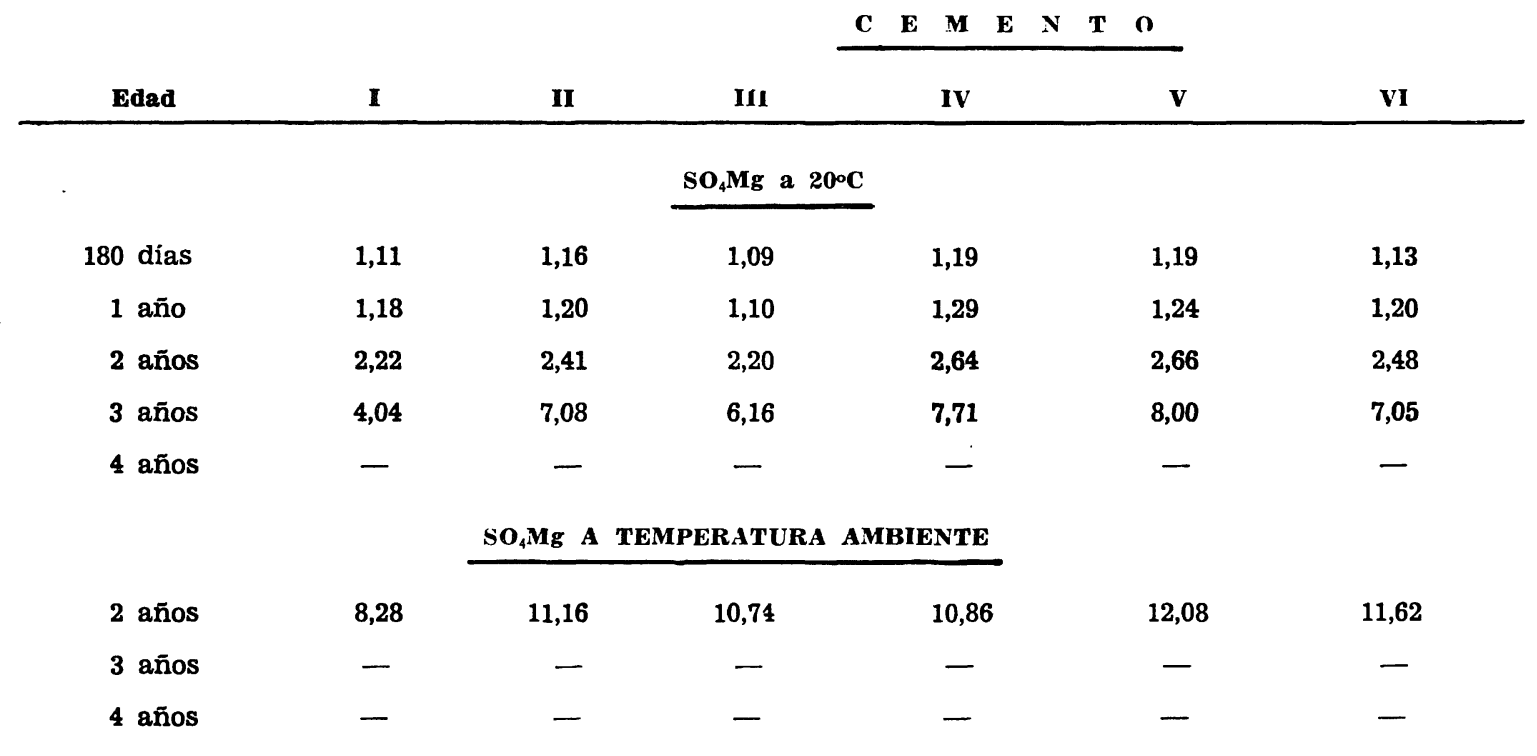

4.4.5.1. En la figura 8 representamos gráficamente los datos de la tabla correspondiente al medio de conservación, agua a $20^{\circ} \mathrm{C}$.

Como se puede observar, ya a la edad de 7 días, los cementos I, II, III, IV, V y VI, tienen mayores resistencias que el cemento $T$ (recuérdese que están molidos a una mayor finura que el cemento $\mathrm{T}$ ), y a 3 días, únicamente el cemento III, tiene una resistencia menor que la del cemento $\mathrm{T}$.

Las cenizas de Puentes reaccionan con más facilidad a primeras edades con el hidróxido cálcico producido en la hidratación del clínker. Al realizar los ensayos mecánicos a igualdad de esparcimiento, cuando empleamos cenizas de Ponferrada, obtenemos sin embargo a cortas edades un nivel resistente más alto. En otros estudios hemos operado a igualdad de relación a/c (0,5 según norma) y en estas condiciones, a primeras edades, el nivel resistente es mayor al utilizar cenizas de Puentes.

4.4.5.2. En la figura 9 representamos los valores de los distintos cementos conservados al aire a temperatura ambiente.

Vemos que los cementos en los que el $10 \%$ del cemento I ha sido sustituido por cenizas, presentan mayor resistencia que el cemento $\mathrm{T}$. En el caso de los cementos en los que el $20 \%$ de cemento I ha sido sustituido por cenizas, a partir de la edad de 90 días, ya superan las resistencias del cemento $\mathrm{T}$.

4.4.5.3. En la figura 10, se representan los valores correspondientes al medio de conservación $\mathrm{SO}_{4} \mathrm{Mg}$ a $20^{\circ} \mathrm{C}$.

La sustitución de parte del cemento I por cenizas volantes, lleva consigo una mayor estabilidad frente al ataque del $\mathrm{SO}_{4} \mathrm{Mg}$.

4.4.5.4. Las probetas del cemento $\mathrm{T}$, conservadas en $\mathrm{SO}_{4} \mathrm{Mg}$ a temperatura ambiente, están a la edad de 2 años, prácticamente deshechas.

4.4.5.4.1. Sólo el aumento de finura (cemento I), y su incidencia en las propiedades puzo-lánicas, y en la cantidad de agua de amasado, origina una menor pérdida de las resistencias mecánicas a esta edad. 


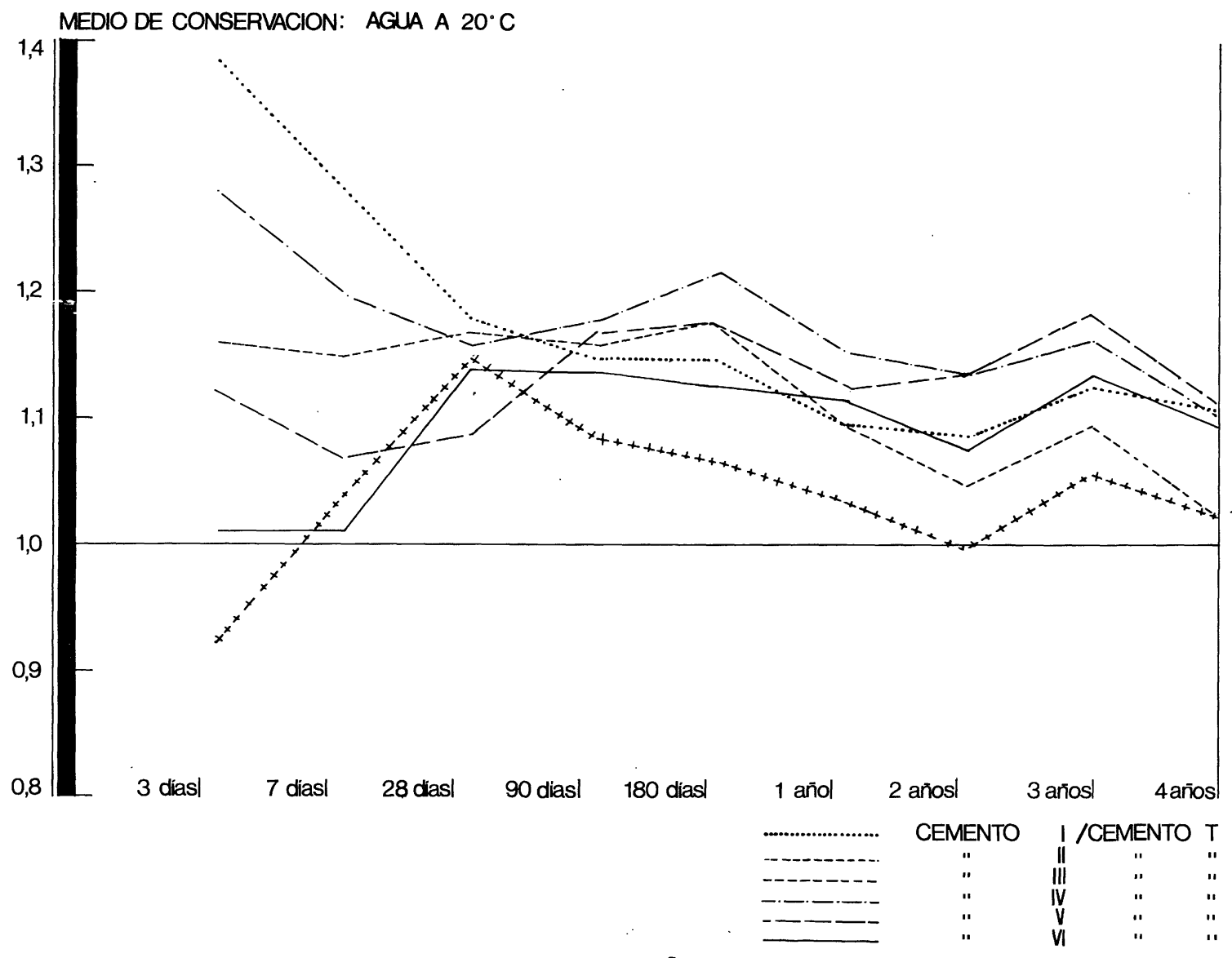

F1g. 8

MEDIO DE CONSERVACION: AIRE A TEMPERATURA AMBIENTE

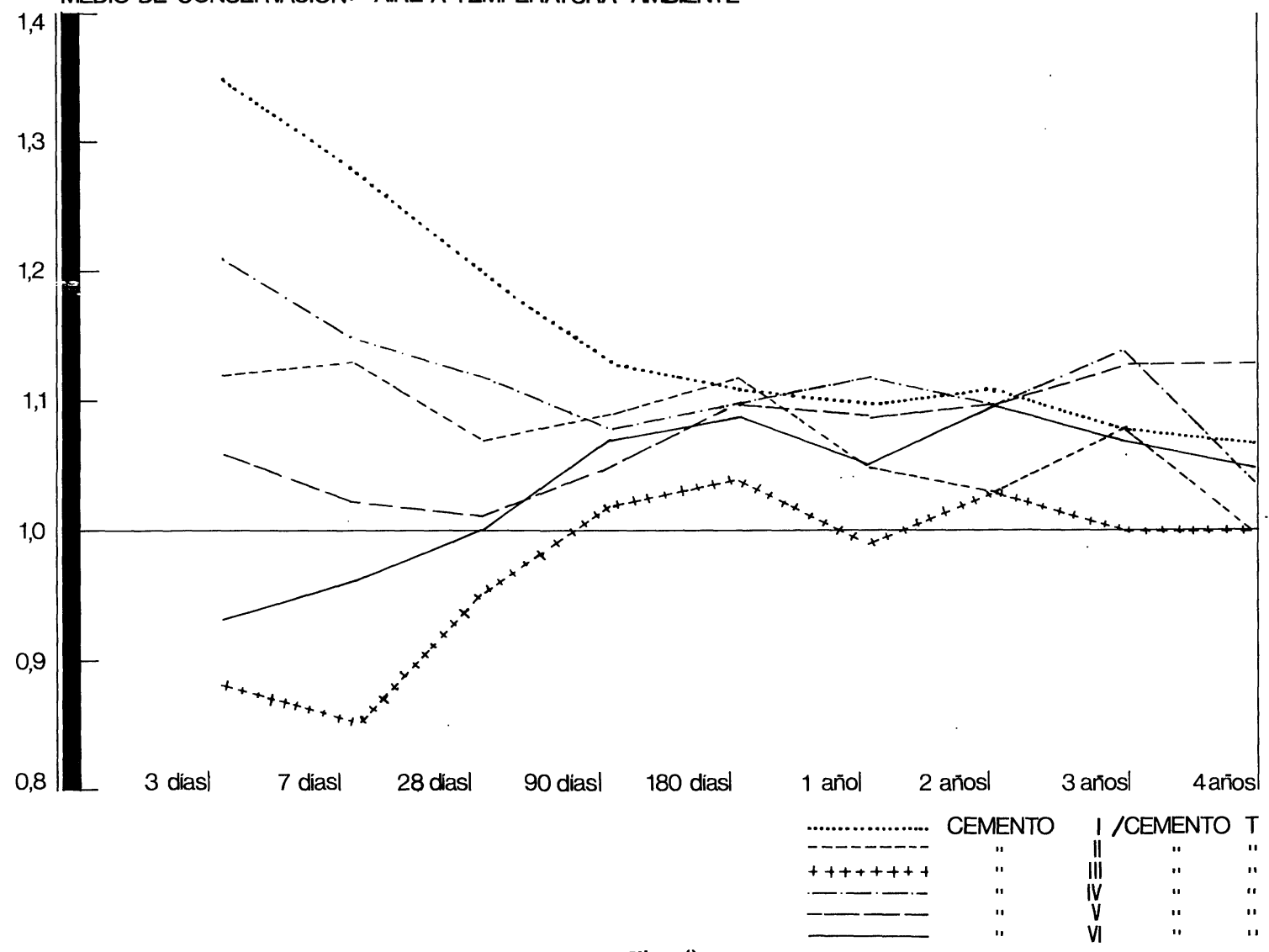




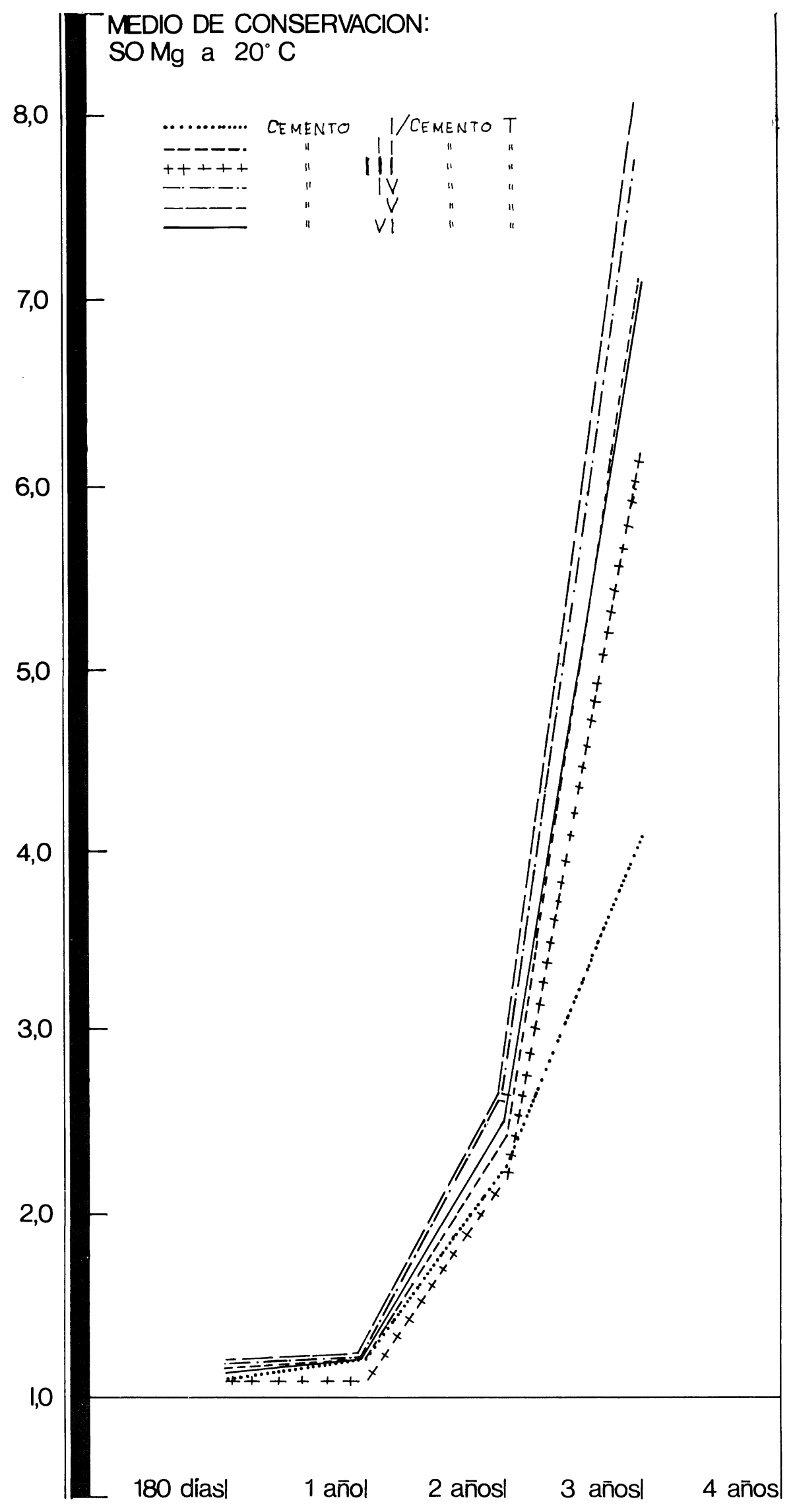

Fig. 10 


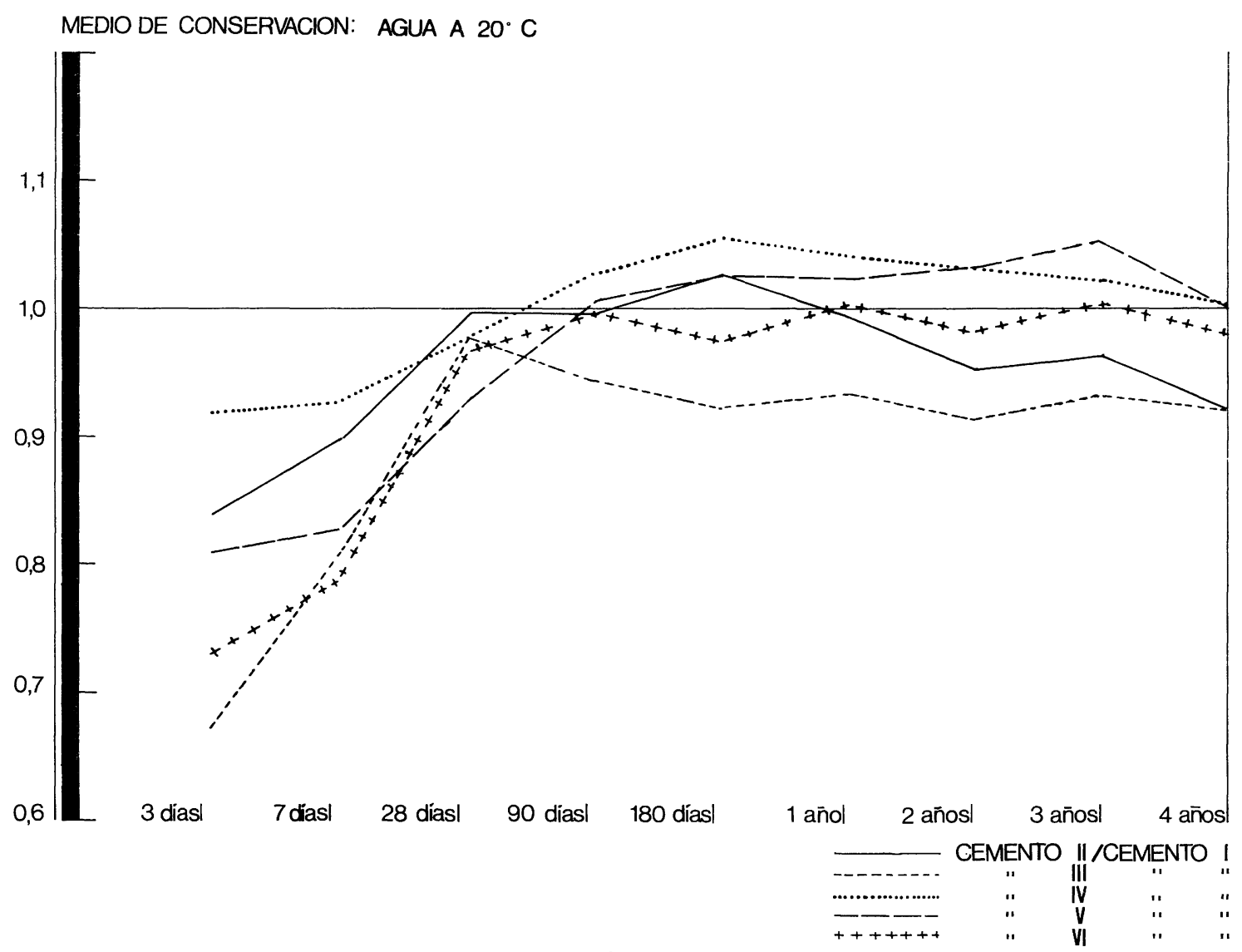

Fig. 11

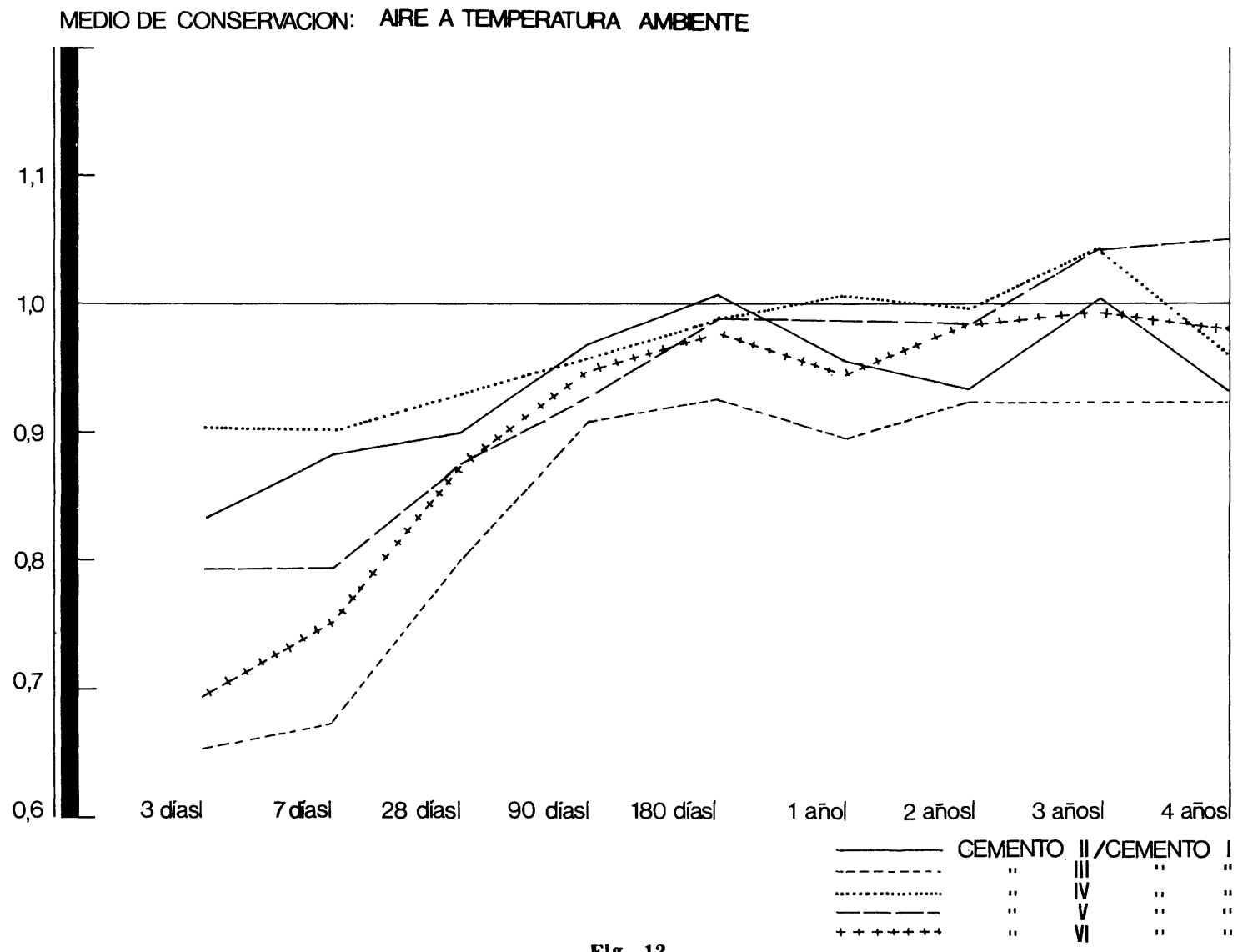


A la edad de 4 años, las probetas de mortero de cemento I, están muy deterioradas después de su conservación en $\mathrm{SO}_{4} \mathrm{Mg}$ tanto a $20^{\circ} \mathrm{C}$ como a temperatura ambiente.

4.4.5.5. Las figuras $11,12,13$ y 14, recogen las resistencias de los cementos obtenidos por una mayor adición de cenizas (II, III, IV, V y VI) referidos al cemento I (cemento T molido) que ya contiene aproximadamente un $10 \%$ de ceniza volante.

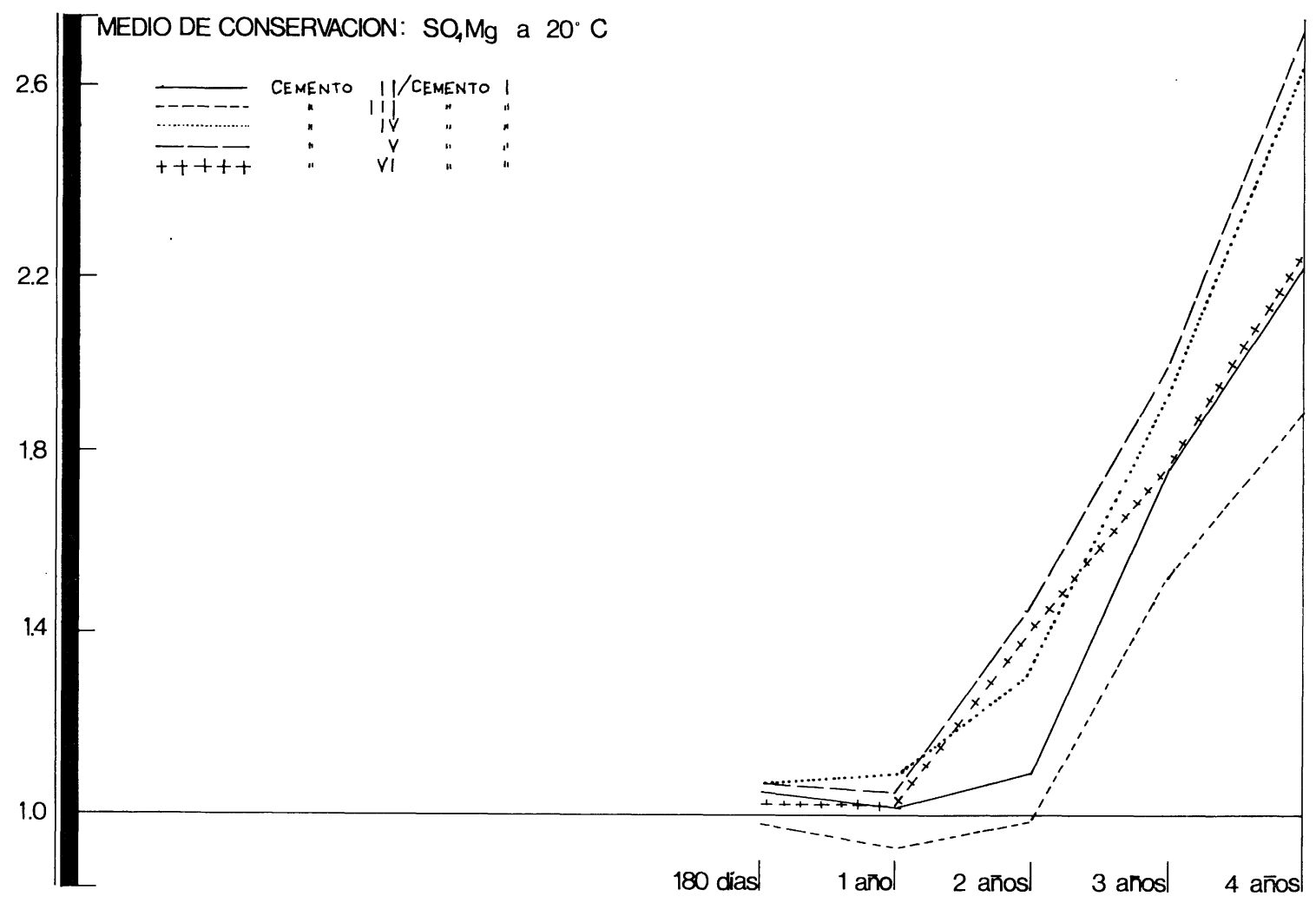

Fig. 13

\section{CONCLUSIONES}

5.1. Teniendo en cuenta la evolución de las resistencias mecánicas en los distintos medios de conservación estudiados y el coste actual de la energía para la producción de clínker, la utilización de estos materiales que tienen unas marcadas propiedades puzolánicas, creemos pueden contribuir al ahorro de energía.

La norma RC-75 admite que los cementos portland con adiciones activas pueden contener no más del $20 \%$ de estos materiales. En Francia, la nueva norma NF15-301, admite para el cemento portland compuesto CPJ una adición menor del $35 \%$.

En nuestros laboratorios continuamos estudiando adiciones en cuantía superior al $20 \%$ en cementos fabricados a escala industrial. Con ellos preparamos morteros con diferentes relaciones agua/cemento, y las probetas se conservan hasta la edad de 7 años en numerosos medios de curado.

5.2. Las cenizas volantes de ambas procedencias, al mezclarlas con el cemento estudiado; aumentan su durabilidad frente a la agresión de disoluciones de $\mathrm{SO}_{4} \mathrm{Mg}$ del $5 \%$ de concentración. 


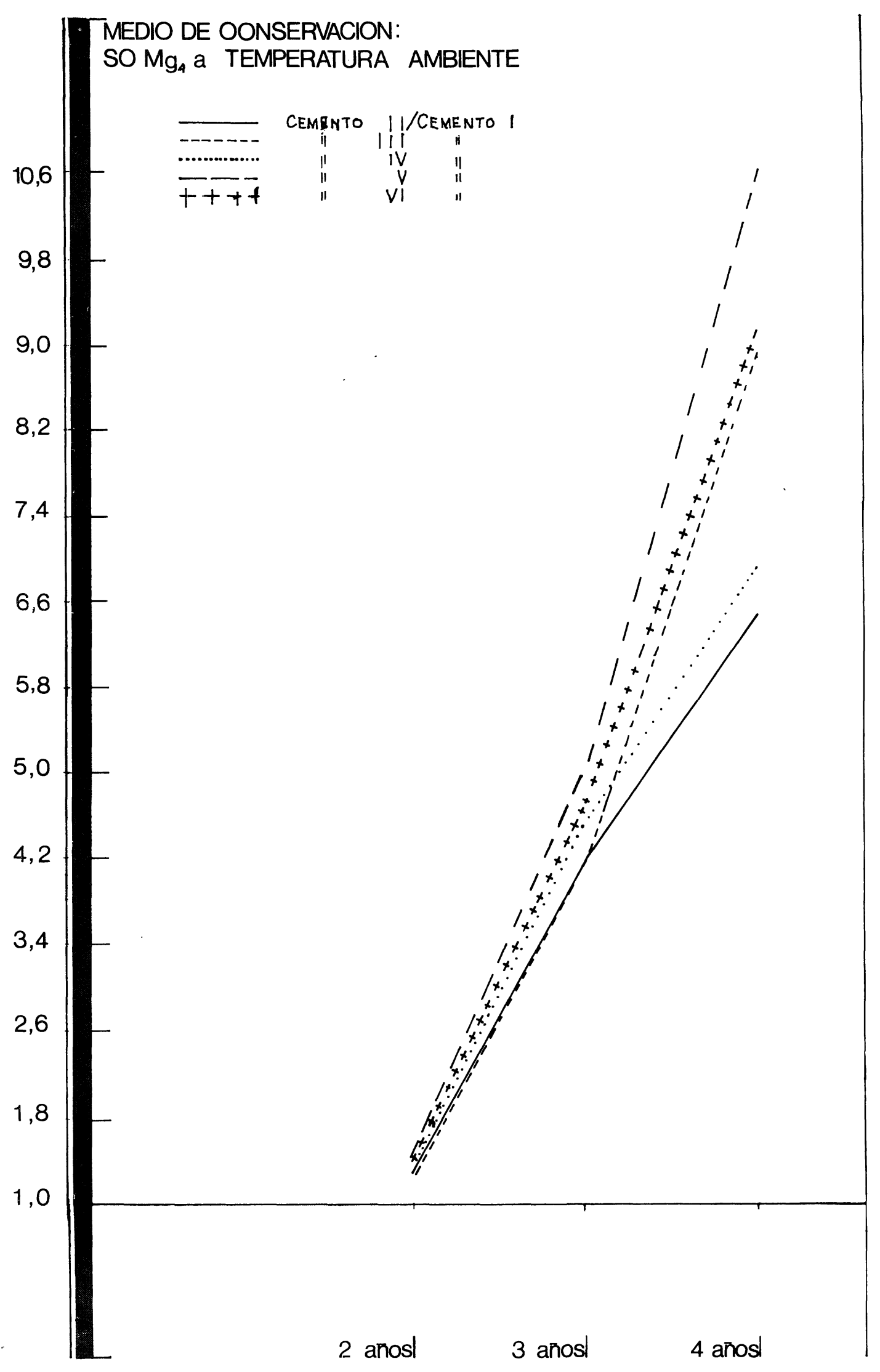

Fig. 14 


\section{BIBLIOGRAFIA}

(1) Venuat, M.: “De l'étude du comportement rhéologique de quelques cendres volantes", revue des Maleriaux: de Construction n. 615 . Edita C.E.R.I.L.H., Paris.

(2) LEA, M. F. : “Química del cemento y del hormigón”. Ed. Edward Arnold. Londres 1960.

(3) Alonso Rammez, J. L.: "Estudio físico-químico y técnico de diversos tipos de cenizas, y su empleo como materiales de construcción". Publicación n. 199 del Laboratorio Central de Ensayos de Materiales de Construcción, Madrid, 1969.

(4) Pliego de condiciones para la recepción de conglomerantes hidráulicos. Instituto Eduado Torroja de la Construcción y del Cemento. PCCH-64. Madrid, 1964.

(5) Recepción de conglomerantes: Pliego de prescripciones técnicas generales para la recepción de cementos RC-75. B.O.E., Madrid, 1975

(6) La nouvelle normalisation française des ciments. Paris, septiembre de 1978. 